\title{
Universiteit
}

Leiden

The Netherlands

\section{Persistently activated, proliferative memory autoreactive B cells promote inflammation in rheumatoid arthritis}

Kristyanto, H.; Blomberg, N.J.; Slot, L.M.; Voort, E.I.H. van der; Kerkman, P.F.; Bakker, A.; ... ; Scherer, H.U.

\section{Citation}

Kristyanto, H., Blomberg, N. J., Slot, L. M., Voort, E. I. H. van der, Kerkman, P. F., Bakker, A., ... Scherer, H. U. (2020). Persistently activated, proliferative memory autoreactive B cells promote inflammation in rheumatoid arthritis. Science Translational Medicine, 12(570). doi:10.1126/scitranslmed.aaz5327

Version: $\quad$ Not Applicable (or Unknown)

License: $\quad$ Leiden University Non-exclusive license

Downloaded from: https://hdl.handle.net/1887/3182270

Note: To cite this publication please use the final published version (if applicable). 


\section{Persistently activated, proliferative memory autoreactive B cells promote inflammation in rheumatoid arthritis}

Hendy Kristyanto ${ }^{1}$, Nienke J. Blomberg ${ }^{1}$, Linda M. Slot ${ }^{1}$, Ellen I.H. van der Voort ${ }^{1}$, Priscilla F. Kerkman $^{1,2}$, Aleida Bakker ${ }^{1}$, Leonie E. Burgers ${ }^{1}$, Robin M. ten Brinck ${ }^{1}$, Annette H.M. van der Helm-van Mil ${ }^{1}$, Hergen Spits ${ }^{3,4}$, Dominique L. Baeten ${ }^{5,6}$, Tom W.J. Huizinga ${ }^{1}$, René E.M. Toes ${ }^{1}$, Hans U. Scherer ${ }^{1, *}$

\footnotetext{
Affiliations:

${ }^{1}$ Department of Rheumatology, Leiden University Medical Centre, 2333RC Leiden, The Netherlands.

${ }^{2}$ Department of Medical Microbiology, University Medical Center Utrecht, 3584CX Utrecht, The Netherlands

${ }^{3}$ Department of Experimental Immunology and Amsterdam Institute of Infection and Immunity, Amsterdam University Medical Center, location AMC, 1105AZ Amsterdam, The Netherlands.

${ }^{4}$ AIMM Therapeutics, 1045BA Amsterdam, The Netherlands

${ }^{5}$ Department of Clinical Immunology and Rheumatology, Amsterdam University Medical Center, location AMC, 1105AZ Amsterdam, The Netherlands.

${ }^{6}$ UCB Pharma, 1070 Brussels, Belgium.
} 
*To whom correspondence should be addressed:

Hans Ulrich Scherer, Department of Rheumatology, Leiden University Medical Centre, P.O. Box 9600, 2300RC Leiden, The Netherlands. Tel.: +31-71-5263598; Fax: +31-71-5266752; e-mail:

h.u.scherer@lumc.nl

One-sentence summary: Proliferative autoreactive B cells secreting proinflammatory cytokines are associated with early, untreated RA and persist in established disease. 
Abstract: Autoreactive B cells mediate autoimmune pathology, but exactly how remains unknown. A hallmark of rheumatoid arthritis (RA), a common autoimmune disease, is the presence of disease-specific anti-citrullinated protein antibodies (ACPA). Here, we showed that ACPA-positive B cells in RA patients strongly expressed $\mathrm{T}$ cell stimulating ligands, produced abundant pro-inflammatory cytokines, and were proliferative while escaping inhibitory signals. This activated state was found at different degrees in different stages of disease: Highest in patients with recent onset RA, moderate in patients with established RA, and far less pronounced in ACPA-positive individuals 'at-risk' for developing disease. Notably, the activated autoreactive B cell response persisted in patients that achieved clinical remission with conventional treatment. ACPA-positive B cells in blood and synovial fluid secreted increased amounts of the chemoattractant interleukin 8 (IL-8), which attracted neutrophils, the most abundant immune cell in arthritic joints. Tetanus toxoid-specific B cells from the same patients exhibited properties of memory B cells without the activation and proliferation phenotype, but these cells transiently acquired a similar proliferative phenotype upon booster vaccination. Together, these data indicated that continuous antigenic triggering of autoreactive B cells occurs in human autoimmune disease and support the emerging concept of immunological activity that persists under treatment even in clinical remission, which may revise our current concept of treatment targets for future therapeutic interventions. In addition, our data pointed to an antibody-independent pathogenic role of ACPA-positive B cells in the inflammatory disease process underlying RA and favor approaches that aim at their antigen-specific inactivation or depletion. 


\section{Introduction}

The role of autoreactive B cells in the pathogenesis of human autoimmune diseases is poorly understood. Autoantibodies are frequently detectable prior to the onset of clinical symptoms. This pre-disease phase of clinically 'silent' autoimmunity can last for years, and the triggers that promote the transition to autoimmune disease are usually unknown. Although autoantibodies themselves may or may not be pathogenic, it is remarkable that many autoimmune diseases are responsive to $\mathrm{CD} 20+\mathrm{B}$ cell depletion. This indicates that B cells, and in particular the auto-reactive subset(s), are crucially involved in disease-relevant pathogenic processes. Hence, it is of considerable importance to understand the phenotypic and functional characteristics of these cells in various phases of autoimmunity and in established disease to decipher both the initiating triggers and the contribution of B cells to human disease.

Rheumatoid arthritis (RA) is a common autoimmune disease that causes inflammation and destruction of joints. Most patients harbor anti-citrullinated proteins antibodies (ACPA), that is antibodies that recognize proteins in which arginine residues have been posttranslationally modified to citrulline. ACPA-positive RA is thought to evolve as a multistep process, in which the break of immunological tolerance to citrullinated antigens precedes the onset of clinical disease (1). ACPA are considered risk factors for disease development and, in established RA, prognosticate erosive joint destruction (2). The transition from ACPA-positive autoimmunity to autoimmune disease is associated with the development of inflammatory joint pain (arthralgia) (3) and an expansion of the ACPA response (1). The latter is marked by rising ACPA serum titers, spreading of epitope recognition and an expanding number of detectable ACPA-isotypes, and likely driven by T cells under the influence of HLA susceptibility-molecules (4-7). How this predisease expansion of the humoral autoimmune response relates to the initiation of joint 
inflammation remains unclear. Potentially, early cartilage damage, fibroblast activation, the generation of citrullinated antigens in the synovium and the migration of ACPA-positive B cells or plasmablasts towards these triggers could be involved.

Established RA is remarkably responsive to $\mathrm{CD} 20+\mathrm{B}$ cell-depleting therapy, a feature shared with several other autoimmune diseases (8). The efficacy of B cell depletion on clinical measures of disease activity is greater in ACPA-positive RA patients than in ACPA-negative patients (9). Clinical improvement upon anti-CD20 therapy precedes the reduction of ACPA serum concentrations (10), and patients can achieve long-term remission despite the persistence of high titer ACPA. These observations suggest that CD20+ B cells - in particular autoreactive, ACPApositive B cells - could play a central role in driving and maintaining the inflammatory disease process. We previously identified ACPA-positive B cells in peripheral blood of RA patients using differentially labelled streptavidin tetramers bound to second generation cyclic citrullinated peptides (CCP2) (11). ACPA-positive B cells circulate in peripheral blood in low frequency as class-switched cells of which most are positive for CD20 and CD27, suggesting a memory phenotype (12). In addition, ACPA-secreting plasmablasts and plasmacells are present in the inflamed joint in which they encounter an inflammatory environment favoring long-term survival (13).

Here, we investigated the molecular characteristics of these cells and defined their pathogenic effector functions. We analyzed protective tetanus toxoid (TT)-specific and autoreactive ACPA-positive B cells directly ex vivo from individual RA patients and from ACPApositive individuals at risk for developing disease. We found that ACPA-positive B cells in patients with established RA display an activated, proliferative memory phenotype and reduced abundance of the inhibitory receptor CD32. This phenotype was most prominent in patients with recent onset 
disease, whereas in the at-risk phase of ACPA-positive arthralgia preceding RA [a phase in which synovial inflammation is absent $(14,15)]$, ACPA-positive B cells showed signs of proliferation with low abundance of other activation markers. ACPA-positive B cells isolated from the inflamed synovial compartment during established disease produced pro-inflammatory cytokines spontaneously ex-vivo, notably the functionally active neutrophil chemoattractant interleukin 8 (IL-8). These data suggested that the onset of RA associates with a strongly activated phenotype of ACPA-positive B cells. These B cells were ideally equipped to communicate with $\mathrm{T}$ cells, remained constantly activated throughout the established phase of disease, proliferating and capable of attracting neutrophils to joints through the secretion of IL-8.

\section{Results}

Identification of autoreactive $B$ cells directed against citrullinated antigens in $R A$

The very low frequency of antigen-specific B cell populations in the circulation challenges their reliable phenotypic characterization by flow cytometric assessment of individual surface markers. Therefore, we opted to compare the phenotype of ACPA-positive B cells not only to the large pool of B cells of undefined specificity, but also to a circulating, antigen-specific B cell population that occurs at a similar frequency in patients. We simultaneously evaluated ACPA-positive and tetanus toxoid (TT)-specific B cells from individual patients. We used a dual staining approach for both specificities employing differentially labelled antigens to increase and ensure the elimination of non-specific background signals $(11,16)$ (Fig. 1A). Blocking experiments were used as additional measure of specificity. Analysis of peripheral blood mononuclear cells (PBMCs) from ACPA+ RA donors revealed that TT-specific B cells circulated in RA patients at a frequency comparable to that of ACPA-positive B cells ( $0.015 \%$ for TT-specific B cells and $0.01 \%$ for ACPA-positive B 
cells) (Fig. 1B). Moreover, > 70\% of TT-specific B cells were positive for CD20 and CD27, indicative of memory B cells (MBCs); 65\% of ACPA-positive B cells displayed this phenotype (Fig. 1C). Unlike ACPA-positive B cells, CD20-CD27 hi plasmablasts or plasmacells were generally absent from the TT-specific compartment, although the differences in these B cell populations were not significant. These data indicated that $\mathrm{CD} 20+\mathrm{CD} 27+\mathrm{B}$ cells, hereafter referred to as MBCs, of both antigen-specific immune responses circulate at similar frequency in the peripheral blood of individual RA patients, which enables direct phenotypic comparison.

We also isolated cells from the synovial fluid of inflamed joints and found that ACPApositive B cells were present at enhanced frequency (Fig. 1B) compared with their frequency in PBMCs. Furthermore, $>50 \%$ of cells were CD20-CD2 $7^{\text {hi }}$ indicative of plasmablasts or plasmacells (Fig. 1D, fig. S1). The frequency of TT-specific B cells was not analyzed in this compartment due to the low number of total B cells, which precluded simultaneous use of the material for concurrent antigen-specific B cell analysis.

The frequency of ACPA-positive MBCs in PBMC correlated with ACPA-IgG plasma concentrations in the samples analyzed (Fig. 1E), confirming previous results (11). In the same patients, no correlation was observed between the frequency of TT-specific MBCs and anti-TT IgG in plasma (Fig. 1E).

Circulating ACPA-positive B cells in established RA display an activated and proliferative phenotype

We evaluated the abundance of selected markers on ACPA-positive and TT-specific B cells in peripheral blood. In patients with established RA ACPA-positive MBCs were larger in size and had higher intensity staining for the stimulatory receptor and mature B cell marker CD19 and 
HLA-DR (human leukocyte antigen- DR isotype) than did TT-specific counterparts from the same individual (Fig. 2A). Moreover, more ACPA-positive B cells were also positive for the ligands CD80 and CD86, which are involved in stimulating T cells, than were TT-specific MBCs or ACPA-negative MBCs. In addition, TT-specific MBCs were negative for the proliferation marker Ki-67, whereas an average of 36\% (range 17\% - 67\%) of ACPA-positive MBCs were also positive for this marker (Fig. 2B, fig. S2). Gene expression analysis by RT-PCR confirmed the enhanced transcript abundance for $C D 19, C D 86$, and $C D 80$ between circulating ACPA-positive MBCs and ACPA-negative MBCs (fig. S3).

Thus, these ACPA-positive B cells had markers of an 'activated' phenotype and of a memory phenotype. Therefore, we refer to them as activated MBCs (aMBCs). The ACPA-positive aMBCs had functionally important phenotypic differences when compared with protective (TTspecific) MBCs in the steady state in patients with established RA.

The frequency of these ACPA-positive aMBCs did not correlate with measures of systemic inflammation (erythrocyte sedimentation rate, fig. S4) or composite disease activity scores (Fig. 2C). Together, these results suggested continuous immune activation of the autoreactive B cell response in patients with established RA, irrespective of disease control by csDMARDs.

ACPA-positive B cells in individuals with joint pain who are 'at-risk' for developing $R A$ In most patients with RA, the presence and expansion of ACPA-positive B cells precedes clinically detectable arthritis (1). Given the activated, proliferative phenotype of ACPA-positive B cells within the $\mathrm{CD} 20+\mathrm{CD} 27+$ compartment in established disease, we investigated the properties of ACPA-positive B cells in ACPA-positive individuals with joint pain (arthralgia) who had so far shown no clinical signs of arthritis (Table 1). 
These individuals harbored similar frequencies of circulating ACPA-positive B cells compared to RA patients with matched ACPA-IgG plasma abundance (fig. S5A, B). A correlation between the frequency of ACPA-positive B cells and ACPA IgG serum abundance was not established in this population, possibly as a consequence of one outlying donor with a high frequency of ACPA-positive B cells (fig. S5C). Upon removal of this donor from the analysis, however, a correlation was noted (Pearson r: 0.81, P 0.02, fig. S5C dotted line) similar to the one observed in RA (Fig. 1E). Furthermore, most ACPA-positive B cells in these individuals were of the MBC $(\mathrm{CD} 20+\mathrm{CD} 27+)$ phenotype (fig. S5D), whereas lower numbers of differentiated plasmablasts or plasmacells (CD20-CD27 ${ }^{\text {hi }}$ ) were detectable compared to patients with established disease (median $0 \%$ in arthralgia versus $4 \%$ in RA for total ACPA-positive B cells).

We focused on the memory cell compartment and compared the phenotype of these cells in the at-risk individuals and those with established RA. We observed similar frequencies of ACPA-positive MBCs that were positive for Ki-67 (median 20\%, range: $0-60 \%$ ) from individuals with arthralgia and those with established RA (Fig. 3A). The other markers indicative of activation, however, were not increased (Fig. 3A). Instead, the abundance of CD19 and HLA-DR expressed by ACPA-positive MBCs was comparable to the steady state TT-specific MBC compartment of RA patients, as was the frequency of cells expressing CD80 and CD86 (Fig. 3B, fig. S6). Thus, despite the increased proportion of cells positive for Ki-67, we observed a far less activated phenotype of ACPA-positive MBCs in individuals with joint pain (arthralgia) that so far lacked the clinical signs of arthritis.

ACPA-positive B cells at the onset of clinical disease 
Given the differential phenotype of ACPA-positive MBCs in patients with established disease compared to individuals with joint pain (arthralgia), we questioned whether the onset of RA associates with autoreactive B cells displaying phenotypic characteristics of aMBC. We evaluated cells from patients with recent onset, ACPA+ RA who had not yet started immunosuppressive medication. In this early, untreated phase of disease, we noted a high abundance and proportion of ACPA-positive MBCs positive for the activation markers that were present in these cells from patients with established disease (Fig. 3A). Indeed, the intensity of HLA-DR staining and the proportion of cells positive for Ki-67 exceeded those observed under treatment.

Although longitudinal samples would be required to firmly establish the differences observed between the phases of arthralgia, early-onset disease, and established RA in individual donors, our data indicated that early-onset, $\mathrm{ACPA}+\mathrm{RA}$ is characterized by a highly activated and proliferative phenotype of ACPA-positive MBCs. The data further suggested that therapeutic intervention partially reduces the activated phenotype of ACPA-positive MBCs. However, in the patients studied, treatment failed to 'silence' these cells to a resting state comparable to that of a 'conventional' memory recall response, in this case directed against TT.

Vaccine-induced TT-specific B cells display a phenotype similar to ACPA-positive B cells

We sought to understand triggers that induce an aMBC phenotype in ACPA-positive B cells. We hypothesized that ACPA-positive aMBC resemble memory cells that have recently left the germinal center in response to detection of an antigen. Such 'recent germinal center emigrant' MBCs exhibit the markers Ki-67, CD27 and elevated expression of CD19, amongst others (17). To test our hypothesis in the human setting, we administered TT booster vaccination to $11 \mathrm{RA}$ patients and assessed the phenotype of circulating TT-specific MBC in 8 out of 11 patients within 
28 days post-vaccination and in the remaining 3 at a later time. Upon vaccination, the intensity of staining for CD19 and HLA-DR, along with the percent of cells positive for CD80 and Ki-67, was higher on TT-specific MBCs compared with that of TT-specific MBCs from RA patients in the steady state (Fig. 3B). The abundance of expression of these activation markers in TT-specific MBCs in the recently vaccinated RA patients was similar to those of ACPA-positive aMBCs (Fig. 3, fig. S6). However, with increasing time after vaccination, the proliferative MBC phenotype of TT-specific MBCs ceased; the proportion of TT-specific MBCs positive for Ki-67 decreased with time after tetanus booster vaccination (Fig. 3C). Although the other activation markers also decreased, the change was not significant over the 42 days that the vaccinated individuals were monitored (fig. S7). These observations suggested that the phenotype of ACPA-positive aMBCs results from continuous, antigen-driven activation of ACPA-positive MBCs. Importantly, these cells fail to reach the state of quiescence.

ACPA-positive B cells in established RA downregulate the inhibitory receptor CD32

B cell activation during conventional immune responses is counterbalanced by inhibitory signals that enable controlled regulation of the immune response. Immune complexes, for example, can engage the inhibitory Fc-gamma-receptor IIb (CD32b), thereby providing negative feedback signals that dampen the activation of antigen-specific B cells. To study whether ACPA-positive aMBCs are susceptible to these control mechanisms, we evaluated the abundance of CD32 on these and TT-specific MBCs. Although TT-specific MBCs in the steady state had similar amounts of $\mathrm{CD} 32$ at the cell surface as was present on the total MBC pool (ACPA-negative MBCs), circulating ACPA-positive aMBCs had reduced abundance of this receptor at the cell surface (Fig. 4A). We also detected reduced amounts of intracellular CD32, indicating that downregulation 
rather than internalization of CD32 is responsible for the reduction at the cell surface (Fig. 4B). These data suggested that ACPA-positive aMBCs are not only continuously activated and driven to proliferate, but these cells escape inhibitory control mechanisms.

\section{Inflammatory cytokine production by ACPA-positive B cells}

B cells can exert multiple effector functions by differentiating into antibody-secreting cells, by presenting antigen to $\mathrm{T}$ cells, and by secreting soluble mediators $(18,19)$. We assessed a range of cytokines produced by ACPA-positive aMBCs to understand how the activated phenotype contributes to disease-relevant processes. ACPA-positive CD20+CD27+ B cells from individual donors were sorted and cultured for 7 days in the presence of irradiated CD40L-positive cells and anti-IgM and anti-IgG Fab 2 fragments to stimulate the B cell receptor (BCR). An equal number of ACPA-negative MBC from the same donors were cultured under the same conditions as controls. Supernatants at day 7 were analyzed for the presence of 11 cytokines (IL-2, IL-4, IL-5, IL-6, IL8, IL-10, IL-12 p70, GM-CSF, IFN- $\gamma$, TNF $\alpha$, and VEGF) using Luminex technology (fig. S8). Compared to ACPA-negative MBCs, ACPA-positive B cells of all donors secreted remarkable amounts of IL-8 (single cell median 51.5, range 1.2 - $239 \mathrm{pg} / \mathrm{ml}$ ) and, to a lesser extent, IL-6 ( single cell median 0.6 , range $0.01-2.7 \mathrm{pg} / \mathrm{ml}$ ) and TNF $\alpha$ (single cell median 0.4 , range $0.01-$ $1.2 \mathrm{pg} / \mathrm{ml}$ ) (Fig. 5A). This secretory capacity was observed despite a lower abundance of surface IgG on ACPA-positive CD20+CD27+ B cells compared to that on ACPA-negative CD20+CD27+ B cells from the same donor (fig. S9).

To assess the relevance of our findings for the inflammatory environment at the site of inflammation, we isolated mononuclear cells directly from synovial fluid (SFMCs). SFMCs were cultured in medium without any stimulation in the presence of Brefeldin A to block protein 
secretion. After 20 hours, cells were harvested, stained for the presence of dead cells and for the presence of surface markers (CD3- a T cell marker, CD14- a monocyte marker (both used to exclude non-B mononuclear cells), CD19, CD20, or CD27); in addition, cells were fixed and permeabilized followed by intracellular staining with CCP2 streptavidin tetramers and antibodies recognizing IL-8, IL-6, or TNF $\alpha$. We detected ACPA-positive B cells that were positive for IL-8 in these cultures without stimulation (Fig. 5B). In all samples, the signal for IL-8, but not for IL-6 and $\mathrm{TNF} \alpha$, from ACPA-positive B cells exceeded that obtained from ACPA-negative B cells from the same compartment.

These results with the circulating ACPA-positive B cells and the ACPA-positive B cells in the synovial fluid showed that these populations have different properties. When stimulated, the ACPA-positive aMBCs from peripheral blood of RA patients produced inflammatory cytokines, especially IL-8 and to a lower extend IL-6 and TNF $\alpha$. Cells from the inflamed synovial fluid produced IL-8 without additional stimulation ex vivo.

\section{IL-8 produced by ACPA-positive B cells induces neutrophil migration}

Given the low frequency of ACPA-positive B cells in peripheral blood, which impedes functional analyses, we studied an immortalized, ACPA-positive human B cell clone $(20,21)$ to assess the functionality of IL-8 produced by ACPA-positive B cells. A TT-specific B cell clone, generated using identical technology, was included as control. ACPA-positive, clonal B cells stimulated with any one of the citrullinated proteins, fibrinogen, vinculin, or myelin basic protein (MBP), which are three well-established citrullinated antigens (22), produced higher amounts of IL-8 compared with cells cultured in the presence of the non-citrullinated versions of the same proteins (Fig. 5C). Differences were observed as to the amount of IL- 8 secretion induced, possibly due to differential 
avidity of the clone for the individual, citrullinated antigens. The TT-specific clone did not react to stimulation with citrullinated proteins (fig. S10). Instead, these cells secreted IL-8 upon BCR stimulation with anti-IgG and anti-IgM or in response to stimulation with both CD40 ligand and anti-IgG and anti-IgM (fig. S10), as did primary human B cells upon BCR ligation in combination with CD40 stimulation (fig. S11).

IL-8 is a chemoattractant for neutrophils (23). Moreover, neutrophils are the most prevalent immune cells in RA joints and contribute to joint damage in RA (24). Therefore, the neutrophil chemoattractant capacity of IL-8 produced by the ACPA-positive B cell clone was assessed. The clonal B cells or the TT-specific B cell clone (as a negative control) were stimulated with CCP2 streptavidin tetramers and soluble CD40L oligomers. At day 3, supernatants from these cultures were tested for IL-8 production by ELISA (Fig. 5D) and used in a neutrophil migration assay. Supernatant of the stimulated, ACPA-positive B cell clone, but not supernatants from the TTspecific B cell clone, enhanced neutrophil migration, which was inhibited by adding a neutralizing mouse anti-human IL-8 antibody (Fig. 5E). Together, these data showed that ACPA-positive B cells can produce functional IL-8, which induced neutrophil migration in vitro.

\section{Discussion}

The functional role of autoreactive B cells in the immune pathogenesis of human autoimmune disease is largely unclear. Hypotheses on the pathogenic involvement of such cells in disease-relevant processes have mainly been generated from murine studies and extrapolated from the study of (secreted) autoantibodies. Moreover, the relevance of these cells in disease pathology is supported by the clinical efficacy of broadly B cell-depleting interventions. In-depth analysis of the autoreactive B cell compartment itself on the cellular level, however, has been hampered by 
difficulties in reliably identifying and isolating these rare, antigen-specific human B cell populations at high purity from patients. Using well-defined clinical phenotypes of a prototypic human autoimmune disease, RA, and of its pre-arthritic, at-risk phase of arthralgia, we here studied the characteristics of autoreactive B cells circulating in the peripheral blood and SF of individual patients. We employed stringent, multimeric, antigen-specific multicolor flow cytometry and cell sorting. We studied B cells directed against citrullinated antigens in this context, because the secreted ACPA repertoire represents the most specific, autoreactive humoral immune response in this disease (2), with numerous in vitro and epidemiologic studies pointing towards its immunepathogenic involvement in the inflammatory disease process $(1,25-30)$. We hypothesized that the phenotypic and functional characterization of these cells could lead to better insights into their potential role in the initiation and maintenance of inflammation; in addition, it could indicate whether these cells are attractive targets for antigen-specific interventions.

TT-specific B cells, representative of a prototypic human memory B cell response to a foreign antigen, were chosen as a suitable comparator due to their similar frequency and differentiation state in peripheral blood. We found that, in RA patients, TT-specific MBCs circulate in a quiescent, resting state, whereas $>30 \%$ (on average) of ACPA-positive B cells actively proliferate and show additional signs of activation. Remarkably, the phenotype of ACPApositive B cells resembled the phenotype of TT-specific B cells shortly after TT-booster vaccination. These data are important because they provide evidence that the autoreactive B-cell response in a prominent human autoimmune disease, RA, is continuously activated and does not reach a quiescent or steady state that is observed for recall responses after infection or vaccination (17). Interestingly, similar to our observations on the protein and mRNA level for selected markers in the autoreactive memory B cells, a distinct transcriptional profile has been described for 
vaccination-induced B cells (17). This profile contrasts with that of conventional memory B cells, suggesting that such cells may undergo differential developmental pathways during germinal center responses. Whether this is also the case for autoreactive aMBC that we identified here remains to be studied.

Furthermore, we found that ACPA-positive B cells had reduced amounts of the inhibitory receptor CD32 and secreted functionally active, pro-inflammatory cytokines upon stimulation, in particular IL-8. In the inflamed joint, we additionally observed B cells that produced such cytokines without ex vivo stimulation. The frequency of ACPA-positive MBCs in the synovial compartment was very low, limiting detailed phenotypic analyses. However, our data suggested that aMBCs could differentiate towards plasmablasts or plasmacells at this site. Together, these results provided evidence for a mechanism of how autoreactive, in this case ACPA-positive, B cells contribute to inflammatory disease processes in RA. Notably, the frequency of ACPApositive aMBCs strongly correlated with ACPA titer in plasma, whereas the frequency of circulating TT-specific MBCs and plasma anti-TT antibodies were disconnected [our data and other's (31)]. Furthermore, we detected ACPA-positive B cells in the memory and the plasmablast or plasmacell populations in circulation, in contrast to TT-specific B cells that circulated primarily as MBCs. These data indicated that the ACPA response is dynamic and suggested that some of the ACPA-positive aMBCs in the circulation originate from recent stimulation events, conceivably from antigen-encounter in germinal centers.

In our phenotypic analysis, ACPA-positive aMBC were also highly positive for costimulatory molecules CD80 and CD86 and had abundant HLA-DR. These features are compatible with a close interaction between these B cells and $\mathrm{T}$ cells, most likely in germinal center or similar structures at extrafollicular sites $(32,33)$. Indeed, BCRs of ACPA-positive B cells are heavily 
mutated, presumably due to extensive T cell help under the influence of certain HLA susceptibility molecules $(1,34)$. Consequently, HLA association, extensive somatic hypermutation. and the presence of class-switched ACPA have been taken as indicators that $\mathrm{T}$ cell help drives the maturation of the ACPA response (1). Notably, this maturation occurs in the pre-arthritic 'at-risk' phase of RA and precedes the clinical transition from arthralgia to overt arthritis (5). Therefore, we hypothesized that the activation status of ACPA-positive B cells would be less pronounced or absent from individuals who had not yet presented with established RA. Indeed, although ACPApositive $\mathrm{B}$ cells from these $\mathrm{ACPA}+$ arthralgia individuals were readily detectable in the circulation and a fraction of them were positive for Ki-67, they closely resembled the resting memory B cell phenotype observed for TT-specific B cells in patients with established RA, at least with regard to the markers tested. In line, no ACPA-positive plasmablasts or plasmacells were observed in the circulation at this stage (Fig. S5D). We deliberately chose individuals that had maintained a status of arthralgia for at least 2 years to enable a clear discrimination between immunological phenotypes. During additional follow-up of 2 years following the analyses, none of the individuals studied here progressed to RA. This could indicate that the degree to which ACPA-positive B cells have the markers described associates with or even precedes disease precipitation. In this context, it is intriguing that at the stage of early onset RA, a proxy for recent progression from arthralgia to arthritis, ACPA-positive MBCs were highly positive for these markers of activation and a marker of proliferation. Thus, we propose that the acquisition of the activated phenotype by ACPApositive $\mathrm{MBC}$ associates with the onset of disease. Hence, it will be important for subsequent work to closely follow the phenotype of ACPA-positive B cells over time in individuals with arthralgia that transition to RA versus those that do not. 
In human autoimmunity, it remains important to understand why and how autoreactive B cells escape from control mechanisms that should normally prevent their emergence and persistence. B cell activation requires balanced signals from activating receptors, such as CD19, and from inhibitory receptors, such as CD32b. Both excess CD19 $(35,36)$ and CD32b deficiency (37) in mice facilitate autoantibody production, supporting the essential roles of CD19 and CD32b in regulating and maintaining peripheral B cell tolerance. We found that ACPA-positive aMBCs had increased amounts of CD19 and reduced amounts of CD32 compared to TT-specific MBCs or ACPA-negative MBCs. This would result in desensitizing ACPA-positive aMBCs from CD32mediated inhibition and, hence, confer resistance to a key regulator that could limit autoreactivity. A mechanism for the reduction of CD32 on ACPA-positive aMBC is CD40 stimulation by T cells $(38)$.

Several results supported the concept of interactions between $\mathrm{T}$ cells and $\mathrm{B}$ cells as driving the ACPA response. Not only does CD40 stimulation of $\mathrm{B}$ cells by $\mathrm{T}$ cells reduce the abundance of CD32, which we observed on the ACPA-positive aMBCs, but a fraction of the ACPA-positive aMBCs were also positive for the $\mathrm{T}$ cell-stimulating proteins CD80 and CD86, which activate CD28 on T cells. CD80/86-CD28 interaction in the cross talk between B and T cells is essential for the activation of autoreactive $\mathrm{T}$ cells and the induction of arthritis in the proteoglycan-induced arthritis mouse model (39). Therefore, it is possible that ACPA-positive B cells partly exert their pathogenic effects in RA by presenting antigens to $T$ cells, thereby recruiting the help required for their own expansion and further differentiation.

Activation and continuous antigenic triggering of B cells can induce the secretion of various cytokines and inflammatory mediators. Upon stimulation, we observed that ACPApositive aMBCs secreted remarkable amounts of IL-8, along with lesser amounts of IL-6 and 
TNF $\alpha$. ACPA-positive B cells from the synovial fluid also produced IL-8 without additional stimulation ex vivo. The IL-8 secreted by these cells is likely functional in vivo, because IL-8 derived from stimulated, ACPA-positive immortalized human B cells induced neutrophil migration in vitro. Indeed, neutrophil migration was mostly but not completely blocked upon inhibition of IL-8, indicating that not only IL-8 but also other factors secreted by these B cells can induce neutrophil migration. Neutrophils are the most abundant cell type in the inflamed synovial compartment of affected joints in established RA (24). By local production in the early phases of arthritis development, activation of ACPA-positive B cells could be highly relevant; IL-8 secretion could stimulate the attraction and influx of neutrophils. In addition, the influx and activation of other innate immune cells, such as macrophages, could also be stimulated, and it is possible that cytokines derived from ACPA-positive B cells could contribute to the local activation of fibroblasts. Expanded B cell clones of unknown specificity have been observed in the peripheral blood of 'at-risk' individuals with arthralgia, and such expanded clones predicted the transition to overt RA (40). Upon arthritis development, these clones disappeared from peripheral blood and were found in synovial tissue. Thus, it is intriguing to speculate that activated, autoreactive B cell clones, whether citrulline-specific or not, migrate to joints and actively contribute to the initiation of arthritis through the secretion of IL-8.

Finally, we observed the activated phenotype of ACPA-positive B cells in all patients with established RA. Most of these received csDMARDs. Notably, there was no association between the phenotype of ACPA-positive aMBCs and measures of disease activity. Thus, patients in clinical remission had activated, autoreactive B cells in their circulation. This suggests that, in RA, clinical remission induced by anti-rheumatic treatment reflects suppression of inflammation rather than quiescence of the underlying immune response. Hence, patients in clinical remission are not 
necessarily in a state of 'immunological remission', which could explain why disease frequently flares in patients upon treatment discontinuation (41). Future studies should therefore evaluate whether the phenotype of the ACPA+ B cell response indeed reflects 'immunological disease activity', and whether 'immunological remission' as defined by a quiescent phenotype of ACPApositive B cells may prognosticate the chance to successfully taper medication.

We acknowledge limitations to our study. First, the cross-sectional nature of our analyses impedes us from concluding about the dynamics of the activated phenotype in individual patients. Because the arthralgia patients analyzed did not progress to RA within the time of follow-up, longitudinal analysis in a prospective setting is necessary to delineate whether the activated phenotype of ACPA-positive B cells precedes or coincides with the onset of RA. B cells in synovial fluid were limited; consequently we could not perform full phenotypic characterization of ACPA-positive B cells and a comparison with TT-specific B cells in this compartment. We only evaluated a small number of markers. Thus, in-depth transcriptomic profiling or proteomic analyses will be necessary to delineate the full pathogenic potential of ACPA-positive B cells to identify potential targets for therapeutic interventions.

In summary, we refined the conceptual understanding of human autoreactive B cells in different phases of a common autoimmune disease, RA. We provided evidence that ACPApositive autoreactive B cells have phenotypic and functional characteristics that fit well with continuous antigen-driven activation and an immune-pathogenic role in this disease. ACPApositive B cells were proliferative, showed markers that facilitate the activation of $\mathrm{T}$ cells, downregulated the inhibitory receptor CD32, upregulated CD19, and actively differentiated into IL-8 and ACPA-producing plasmablasts or plasmacells. This phenotype was most prominent at the onset of disease. In addition, it persisted in patients that reached treatment-induced clinical 
remission, which provides evidence for the concept of 'immunological remission' as a relevant treatment target in RA. Therefore, specific depletion or 'silencing' of this activated B cell compartment is a relevant and testable treatment strategy for future therapeutic interventions.

\section{Materials and Methods}

\section{Study design}

The study was designed as a cross-sectional analysis of peripheral blood and synovial fluid samples of individual patients with ACPA+ RA or ACPA+ clinically suspect arthralgia (CSA (42)) or of healthy individuals. No therapeutic intervention was administered to patients for the purpose of the study. Patients who had received prior treatment with biologic agents were excluded. The researcher performing sample work-up and analysis was aware of the diagnosis but blinded to the clinical parameters of the patients. Sample numbers and experimental replicates are provided in the figure legends.

\section{Patients and healthy individuals}

Peripheral blood and synovial fluid from ACPA + RA patients were obtained at the outpatient clinic of the Department of Rheumatology at Leiden University Medical Centre (LUMC). All RA patients met the 2010 ACR/EULAR criteria for RA at the time of diagnosis. Treatment regimens included csDMARDs and glucocorticoids. All patients were naïve for biologic agents and had never received B cell-depleting therapy. Individuals with arthralgia were recruited from the CSA cohort (43) of the LUMC based on their ACPA positivity. None of these had so far developed clinical signs of arthritis and, hence, did not meet the 2010 ACR/EULAR criteria for RA at the time of sampling. Selected RA patients received TT booster vaccination in the untreated phase of 
recent onset disease; peripheral blood was sampled within a maximum of 42 days after vaccination. All donors gave written informed consent. Permission for conduct of the study was obtained from the ethical review board of LUMC.

\section{Cell isolation and culture}

To determine the concentration of CCP2-tetramers for flow cytometry experiments, HEK 293T cells expressing cell-surface ACPA (HEK $\left.{ }^{\mathrm{ACPA}-\mathrm{TM}}\right)$ were generated by transducing HEK $293 \mathrm{~T}$ cells with lentiviral vectors encoding the transmembrane antibody against CitFib1.1, as previously described (11). These cells were cultured in Dulbecco Modified Eagle Medium (DMEM) supplemented with $8 \%$ heat-inactivated fetal calf serum (FCS), penicillin/streptomycin (100 $\mathrm{U} / \mathrm{ml}$ ), $2 \mathrm{mM}$ Glutamax, and $1 \mu \mathrm{g} / \mathrm{ml}$ puromycin (from InvivoGen).

To assess the abundance or presence of activation and inhibitory markers, PBMCs were isolated from $50 \mathrm{ml}$ of heparinized peripheral blood using Ficoll-Paque gradient centrifugation and stored overnight at $4{ }^{\circ} \mathrm{C}$ in Iscove's Modified Dulbecco's Medium (IMDM) supplemented with $8 \%$ FCS, $100 \mathrm{U} / \mathrm{ml}$ penicillin/streptomycin, and $2 \mathrm{mM}$ Glutamax (the combination is referred to as culture medium). For the same purpose, synovial fluid from swollen joints was obtained by arthrocentesis and centrifuged; the pellet was harvested and suspended in PBS (pH 7,4) at room temperature. SFMCs were isolated and stored at $4^{\circ} \mathrm{C}$ in culture medium.

To determine cytokine secretion by Luminex assay, sorted ACPA-positive or control cells were cultured in IMDM supplemented with $10 \%$ FCS, $100 \mathrm{U} / \mathrm{ml}$ penicillin/streptomycin, $2 \mathrm{mM}$ Glutamax, and $50 \mu \mathrm{g} / \mathrm{ml}$ gentamycin in a 96-well flat bottom plate on a layer of 7000 Radirradiated murine fibroblasts positive for human CD40 ligand (CD40L, $5 \times 10^{3}$ cells/well) in the 
presence of $5 \mu \mathrm{g} / \mathrm{ml}$ anti-IgM and $\operatorname{IgG~F}\left(\mathrm{ab}^{\prime}\right)_{2}$-fragments (Jackson Immunoresearch Laboratories). Supernatants were harvested after 7 days of incubation.

To assess the production of cytokines from SFMCs, synovial fluid was treated with 100 $\mu \mathrm{g} / \mathrm{ml}$ hyaluronidase (Sigma) for 30 minutes at $37^{\circ} \mathrm{C}$ before SFMC isolation as described above. SFMCs were then cultured with culture medium and $2 \mu \mathrm{g} / \mathrm{ml}$ brefeldin A for 20 hours before staining.

Immortalized B cells recognizing CCP2 or tetanus toxoid (TT) were generated by transducing antigen-specific human memory B cells with retroviruses encoding Bcl-6 and Bcl-xL. Transduced cells can be visualized by their expression of GFP. Immortalized clones were cultured in the presence of irradiated CD40L-positive cells and mouse interleukin-21-Fc (mIL21-Fc), as previously described $(20,21)$.

To assess IL- 8 production by immortalized ACPA B cells, $1 \times 10^{5}$ immortalized ACPA+ or TT + B cells were cultured with $1 \times 10^{4}$ irradiated CD40L-positive cells and $30 \mu \mathrm{g} / \mathrm{ml}$ citrullinated myelin basic protein (cit-MBP), $100 \mu \mathrm{g} / \mathrm{ml}$ cit-vinculin, $60 \mu \mathrm{g} / \mathrm{ml}$ cit-fibrinogen, or their mock citrullinated proteins. Supernatants were collected after 3 days of culture.

To assess neutrophil migration, neutrophils were isolated from peripheral blood of healthy volunteers using dextran sedimentation and Ficoll-Paque gradient centrifugation, as previously described (44). The purity of such isolations was $>90 \%$. Supernatants were collected from cultured, immortalized ACPA + and TT + B cells $\left(1 \times 10^{5}\right.$ each $)$, which were stimulated with 100 $\mu \mathrm{g} / \mathrm{ml} \mathrm{CCP2-avidin} \mathrm{and} 100 \mathrm{ng} / \mathrm{ml}$ soluble MEGA-CD40L (Enzo) for 3 days.

\section{Antigen labelling}


To identify B cells specific for citrullinated-antigens by flow cytometry, biotinylated CCP2 or its arginine control variant (CArgP2) were conjugated with BrilliantViolet 605 (BV605) or Allophycocyanin (APC)-labelled streptavidin or phycoerythrin (PE)-labelled extravidin (Sigma, Lifetechnologies, Biolegend), as previously described (11). To identify TT-specific B cells, TT (Statens Serum Institut) was labelled with APC or PE using AnaTag labelling kit, according to the manufacturer's instruction (AnaSpec). Optimal concentrations of labelled CCP2 or CArgP2 tetramers and of labelled TT were obtained by titration on HEK $^{\text {ACPA-TM }}$ and wild-type HEK $293 \mathrm{~T}$ cells or on immortalized TT-specific B cells, respectively.

\section{Flow cytometry}

To stain for activation markers on both ACPA-positive and TT-specific B cells, PBMCs were divided into three equal fractions and stained for dead cells using fixable violet dead cell stain kit (Molecular Probes). Two fractions were subsequently stained with CCP2-APC, CCP2-BV605 and CArgP2-PE tetramers, anti-CD3 Pacific Blue (PB, clone UCHT1), CD14 PB (clone M5E2), CD19 APC-Cy7 (clone Sj25C1), CD20 Alexa Fluor 700 (AF700, clone 2H7, Biolegend), CD27 PE-Cy7 (clone M-T271), anti-CD80 Brilliant Blue 515 (clone L307.4), CD86 Brilliant Violet 510 (clone 2331), HLA-DR PE-CF594 (clone G46-6) or their respective isotype control antibodies (except anti-CD20, all BD Biosciences). To stain for the inhibitory marker CD32, anti-CD32 PE-CF594 (clone FLI8.26; BD Biosciences) or its isotype control antibody were used. The third fraction was stained with TT-APC, TT-PE, and the same labelled antibodies as in fraction 1. Subsequently, all fractions were fixed, permeabilized (Fixation/Permeabilization Concentrate, Diluent, and Buffer by eBioscience) and stained with anti-Ki-67 PerCP-eFluor710 (clone 20Raj1, eBioscience) or an appropriate isotype control. 
To test the staining specificity of TT-specific B cells, cells were preincubated with 10x excess of TT or BSA before staining with labelled TT.

To stain for intracellular cytokines, unstimulated SFMCs (see Cell Isolation and Culture) were divided into two fractions. Both were stained for dead cells, CD3, CD14, CD19, CD20, and

CD27. Subsequently, cells were fixed, permeabilized (BD Perm/Wash ${ }^{\mathrm{TM}}$, BD Biosciences), and stained intracellularly with CCP2-BV605 and CCP2-APC tetramers. One fraction was additionally stained with anti-IL-8 PE (clone G265-8), anti-IL-6 FITC (clone AS12), and anti-TNF- $\alpha$ PECF594 (clone Mab11) ( all from BD Biosciences). The other fraction was additionally stained with the isotype controls of these antibodies. All flow cytometry measurements were conducted using a BD LSRFortessa (BD Biosciences).

\section{Cell sorting}

PBMCs were stained using markers for dead cells, CD3, CD14, CD19, CD20, CD27, CCP2-APC, CCP2-BV605, and CArgP2-PE. ACPA-positive memory B cells (dead cell staining-, CD3-, CD14-, CD19+, CD20+, CD27+, CCP2+/+, CArgP-) and tetramer-negative memory B cells (CCP2-/-) were sorted using BD FACSAria III (BD Biosciences).

\section{Protein citrullination}

Citrullinated vinculin, fibrinogen, and MBP were generated by incubating overnight $1 \mathrm{mg} / \mathrm{ml}$ of vinculin435-739 (kindly provided by Sander van Kasteren, Leiden Institute of Chemistry), $1 \mathrm{mg} / \mathrm{ml}$ fibrinogen (Sigma), and $1 \mathrm{mg} / \mathrm{ml}$ MBP (Sigma) with $0.1 \mathrm{M}$ Tris-HCL, $10 \mathrm{mM} \mathrm{CaCl}_{2}$, and PAD4 (Sigma) $5 \mathrm{U}$ for vinculin, $5 \mathrm{U}$ for fibrinogen, and $3 \mathrm{U}$ for MBP. Unmodified proteins were generated by incubating the proteins with PAD4 and Tris-HCL without $\mathrm{CaCL}_{2}$. 
ELISA

The presence of ACPA-IgG and anti-TT IgG in patient's plasma was assessed by ELISA based on reactivity against biotinylated-CCP2 or $\mathrm{TT}$, respectively. Biotinylated-CCP2 was coupled to streptavidin-coated ELISA plates and TT was directly coated to C96 Maxisorp Nunc-immuno plates (Thermo-Scientific). Plasma-heparin samples were tested at a 1:50 dilution and higher. Bound ACPA and anti-TT IgG were detected by polyclonal rabbit human IgG HRP (DAKO) and stained with ABTS.H2O2 (Sigma-Aldrich). The presence of secreted IL-8 by stimulated immortalized B cells was assessed by Human IL-8 ELISA (Ready-SET-Go! 2 ${ }^{\text {nd }}$ generation, Affymetrix eBioscience) according to the manufacturer's instruction.

\section{Luminex assay}

To assess the cytokine production by ACPA-positive memory B cells, supernatants of cultured ACPA-positive and tetramer-negative memory B cells were analyzed using high sensitivity Luminex assay (R\&D Systems Magnetic Luminex Performance Assay) for the production of human IL-2, IL-4, IL-5, IL-6, IL-8, IL-10, IL-12 p70, GM-CSF, IFN- $\gamma$, TNF- $\alpha$, and VEGF, according to the manufacturer's instruction.

\section{Neutrophil migration assay}

The capacity of IL-8 produced by immortalized ACPA-positive B cells to induce neutrophil migration was assessed by adding the supernatant of stimulated cells to the bottom of a ChemoTx Disposable Chemotaxis 96-well System ( $3 \mu \mathrm{m}$ diameter filter; Neuro Probe). Neutrophils $\left(2 \times 10^{5}\right)$ were added on top of the filter for 90 minutes according to the manufacturer's instruction. As a 
positive control, $100 \mathrm{ng} / \mathrm{ml} \mathrm{rhL-8} \mathrm{(Biolegend)} \mathrm{was} \mathrm{added} \mathrm{to} \mathrm{the} \mathrm{culture} \mathrm{medium.} \mathrm{To} \mathrm{test} \mathrm{for}$ specificity of the effect of IL-8, the supernatant was incubated with $50 \mu \mathrm{g} / \mathrm{ml}$ mouse anti-IL-8 blocking antibody (clone 807 , abcam) for $1 \mathrm{~h}$ at $37^{\circ} \mathrm{C}$ prior to the assay. The number of migrated neutrophils was assessed by flow cytometry. To correct for technical variations in cell counts obtained by flow cytometry, $10 \mu 1$ Cell Counting Beads (+/- 10,000 beads; Invitrogen) were added to fixed neutrophils and mixed thoroughly before measurement on a BD LSRFortessa (BD Biosciences). The number of migrated neutrophils was normalized to the number of beads added to the sample.

\section{Real-time PCR of isolated B cell populations}

Pools of $8-30 \mathrm{CD} 19^{+} \mathrm{CD} 20^{+} \mathrm{CD} 27^{+} \mathrm{CCP} 2^{+/+} \mathrm{CArgP} 2^{-} \mathrm{B}$ cells and respective $\mathrm{CCP} 2^{-}$control $\mathrm{B}$ cells were obtained by FACS from patients with ACPA+ RA. Cells were subjected to mRNA isolation and cDNA synthesis according to Picelli et al. (SmartSeq2 protocol)(45). cDNA was pre-amplified (18 - 23 cycles) using KAPA HiFi Hotstart Readymix followed by purification with Ampure XP beads. RT-PCRs were performed using 1:20 diluted cDNA and SYBR green. Negative controls included $\mathrm{H}_{2} \mathrm{O}$ in PCR reactions and 'empty wells' included from the sorting procedure. Primer sequences are provided in Table 2.

\section{Statistical analysis}

Statistical analyses were performed using GraphPad Prism 6.02. Correlations and comparisons were assessed using non-parametric tests. Mann-Whitney test was used to compare data from unpaired samples (for example, healthy donors versus RA patients); Wilcoxon signed-rank test was used to compare paired data from individual RA patients. In case of multiple comparisons, 
one-way ANOVA was used followed by Dunn's test to correct for multiple testing. Specific information is provided in the figure legends. 


\section{Supplementary Materials}

Fig. S1. Subsets of ACPA-positive B cells in synovial fluid of inflamed joints from patients with RA.

Fig. S2. Histogram plots depicting the positivity for CD80, CD86, or Ki-67 in ACPA-positive $(\mathrm{ACPA}+)$, tetanus toxoid-specific (TT+), and bulk (ACPA-) MBC populations.

Fig. S3. Relative gene expression of B cell phenotypic markers in ACPA-positive and noncitrulline-reactive MBCs.

Fig. S4. Correlation analysis between systemic inflammation and the characteristics of ACPApositive MBCs.

Fig. S5. Characteristics of ACPA-positive B cells in individuals with ACPA+ arthralgia.

Fig. S6. Phenotype of ACPA-positive B cells in different disease phases compared to TTspecific B cells in the steady state and upon recent vaccination in patients with RA.

Fig. S7. Correlation between the proportion of TT-specific MBCs positive for CD80 or CD86, and abundance of CD19 or HLA-DR and time after TT vaccination in untreated RA patients.

Fig. S8. Cytokine secretion by ACPA-positive MBCs.

Fig. S9. Abundance of IgG on CD20+CD27+ ACPA-positive and ACPA-negative B cells from RA patient peripheral blood.

Fig. S10. Production of IL-8 by TT-specific and ACPA-positive, immortalized B cell clones triggered by various stimulants.

Fig. S11. Production of IL-8 by B cells from healthy individuals upon different stimulation conditions and at different time points after stimulation.

Data S1. Subject-level data for experiments with $\mathrm{n}<20$ donors/replicates. 


\section{References:}

1. H. U. Scherer, T. W. J. Huizinga, G. Kronke, G. Schett, R. E. M. Toes, The B cell response to citrullinated antigens in the development of rheumatoid arthritis. Nat Rev Rheumatol 14, 157-169 (2018).

2. A. Willemze, L. A. Trouw, R. E. Toes, T. W. Huizinga, The influence of ACPA status and characteristics on the course of RA. Nat Rev Rheumatol 8, 144-152 (2012).

3. L. E. Burgers, H. W. van Steenbergen, R. M. Ten Brinck, T. W. Huizinga, A. H. van der Helm-van Mil, Differences in the symptomatic phase preceding ACPA-positive and ACPA-negative RA: a longitudinal study in arthralgia during progression to clinical arthritis. Ann Rheum Dis 76, 1751-1754 (2017).

4. D. van der Woude, S. Rantapaa-Dahlqvist, A. Ioan-Facsinay, C. Onnekink, C. M. Schwarte, K. N. Verpoort, J. W. Drijfhout, T. W. Huizinga, R. E. Toes, G. J. Pruijn, Epitope spreading of the anti-citrullinated protein antibody response occurs before disease onset and is associated with the disease course of early arthritis. Ann Rheum Dis 69, 1554-1561 (2010).

5. P. Suwannalai, L. A. van de Stadt, H. Radner, G. Steiner, H. S. El-Gabalawy, C. M. Zijde, M. J. van Tol, D. van Schaardenburg, T. W. Huizinga, R. E. Toes, L. A. Trouw, Avidity maturation of anti-citrullinated protein antibodies in rheumatoid arthritis. Arthritis Rheum 64, 1323-1328 (2012).

6. L. A. van de Stadt, M. H. de Koning, R. J. van de Stadt, G. Wolbink, B. A. Dijkmans, D. Hamann, D. van Schaardenburg, Development of the anti-citrullinated protein antibody repertoire prior to the onset of rheumatoid arthritis. Arthritis Rheum 63, 3226-3233 (2011).

7. A. H. Hensvold, P. K. Magnusson, V. Joshua, M. Hansson, L. Israelsson, R. Ferreira, P. J. Jakobsson, R. Holmdahl, L. Hammarstrom, V. Malmstrom, J. Askling, L. Klareskog, A. I. Catrina, Environmental and genetic factors in the development of anticitrullinated protein antibodies (ACPAs) and ACPA-positive rheumatoid arthritis: an epidemiological investigation in twins. Ann Rheum Dis 74, 375-380 (2015).

8. J. C. Edwards, L. Szczepanski, J. Szechinski, A. Filipowicz-Sosnowska, P. Emery, D. R. Close, R. M. Stevens, T. Shaw, Efficacy of B-cell-targeted therapy with rituximab in patients with rheumatoid arthritis. $N$ Engl J Med 350, 2572-2581 (2004).

9. K. Chatzidionysiou, E. Lie, E. Nasonov, G. Lukina, M. L. Hetland, U. Tarp, C. Gabay, P. L. van Riel, D. C. Nordstrom, J. Gomez-Reino, K. Pavelka, M. Tomsic, T. K. Kvien, R. F. van Vollenhoven, Highest clinical effectiveness of rituximab in autoantibody-positive patients with rheumatoid arthritis and in those for whom no more than one previous TNF antagonist has failed: pooled data from 10 European registries. Ann Rheum Dis 70, 15751580 (2011).

10. R. M. Thurlings, K. Vos, C. A. Wijbrandts, A. H. Zwinderman, D. M. Gerlag, P. P. Tak, Synovial tissue response to rituximab: mechanism of action and identification of biomarkers of response. Ann Rheum Dis 67, 917-925 (2008).

11. P. F. Kerkman, E. Fabre, E. I. van der Voort, A. Zaldumbide, Y. Rombouts, T. Rispens, G. Wolbink, R. C. Hoeben, H. Spits, D. L. Baeten, T. W. Huizinga, R. E. Toes, H. U. Scherer, Identification and characterisation of citrullinated antigen-specific B cells in peripheral blood of patients with rheumatoid arthritis. Ann Rheum Dis 75, 1170-1176 (2016).

12. U. Klein, K. Rajewsky, R. Kuppers, Human immunoglobulin (Ig)M+IgD+ peripheral blood B cells expressing the CD27 cell surface antigen carry somatically mutated variable 
region genes: CD27 as a general marker for somatically mutated (memory) B cells. $J$ Exp Med 188, 1679-1689 (1998).

13. P. F. Kerkman, A. C. Kempers, E. I. van der Voort, M. van Oosterhout, T. W. Huizinga, R. E. Toes, H. U. Scherer, Synovial fluid mononuclear cells provide an environment for long-term survival of antibody-secreting cells and promote the spontaneous production of anti-citrullinated protein antibodies. Ann Rheum Dis 75, 2201-2207 (2016).

14. M. J. de Hair, M. G. van de Sande, T. H. Ramwadhdoebe, M. Hansson, R. Landewe, C. van der Leij, M. Maas, G. Serre, D. van Schaardenburg, L. Klareskog, D. M. Gerlag, L. G. van Baarsen, P. P. Tak, Features of the synovium of individuals at risk of developing rheumatoid arthritis: implications for understanding preclinical rheumatoid arthritis. Arthritis Rheumatol 66, 513-522 (2014).

15. M. G. van de Sande, M. J. de Hair, C. van der Leij, P. L. Klarenbeek, W. H. Bos, M. D. Smith, M. Maas, N. de Vries, D. van Schaardenburg, B. A. Dijkmans, D. M. Gerlag, P. P. Tak, Different stages of rheumatoid arthritis: features of the synovium in the preclinical phase. Ann Rheum Dis 70, $772-777$ (2011).

16. S. E. Townsend, C. C. Goodnow, R. J. Cornall, Single epitope multiple staining to detect ultralow frequency B cells. Journal of Immunological Methods 249, 137-146 (2001).

17. A. H. Ellebedy, K. J. Jackson, H. T. Kissick, H. I. Nakaya, C. W. Davis, K. M. Roskin, A. K. McElroy, C. M. Oshansky, R. Elbein, S. Thomas, G. M. Lyon, C. F. Spiropoulou, A. K. Mehta, P. G. Thomas, S. D. Boyd, R. Ahmed, Defining antigen-specific plasmablast and memory B cell subsets in human blood after viral infection or vaccination. Nat Immunol 17, 1226-1234 (2016).

18. S. W. Jackson, N. S. Kolhatkar, D. J. Rawlings, B cells take the front seat: dysregulated B cell signals orchestrate loss of tolerance and autoantibody production. Curr Opin Immunol 33, 70-77 (2015).

19. T. Dorner, A. M. Jacobi, P. E. Lipsky, B cells in autoimmunity. Arthritis Res Ther 11, 247 (2009).

20. M. J. Kwakkenbos, S. A. Diehl, E. Yasuda, A. Q. Bakker, C. M. van Geelen, M. V. Lukens, G. M. van Bleek, M. N. Widjojoatmodjo, W. M. Bogers, H. Mei, A. Radbruch, F. A. Scheeren, H. Spits, T. Beaumont, Generation of stable monoclonal antibody-producing B cell receptor-positive human memory B cells by genetic programming. Nat Med 16, 123128 (2010).

21. K. Germar, C. M. Fehres, H. U. Scherer, N. van Uden, S. Pollastro, N. Yeremenko, M. Hansson, P. F. Kerkman, E. I. H. van der Voort, E. Reed, H. Maassen, M. J. Kwakkenbos, A. Q. Bakker, L. Klareskog, V. Malmstrom, N. de Vries, R. E. M. Toes, K. Lundberg, H. Spits, D. L. Baeten, Generation and Characterization of Anti-Citrullinated Protein Antibody-Producing B Cell Clones From Rheumatoid Arthritis Patients. Arthritis Rheumatol 71, 340-350 (2019).

22. A. Ioan-Facsinay, H. el-Bannoudi, H. U. Scherer, D. van der Woude, H. A. Menard, M. Lora, L. A. Trouw, T. W. Huizinga, R. E. Toes, Anti-cyclic citrullinated peptide antibodies are a collection of anti-citrullinated protein antibodies and contain overlapping and nonoverlapping reactivities. Ann Rheum Dis 70, 188-193 (2011).

23. R. C. Russo, C. C. Garcia, M. M. Teixeira, F. A. Amaral, The CXCL8/IL-8 chemokine family and its receptors in inflammatory diseases. Expert Rev Clin Immunol 10, 593-619 (2014). 
24. S. W. Edwards, M. B. Hallett, Seeing the wood for the trees: the forgotten role of neutrophils in rheumatoid arthritis. Immunol Today 18, 320-324 (1997).

25. N. Renner, G. Kronke, J. Rech, M. Uder, R. Janka, L. Lauer, D. Paul, B. Herz, P. Schlechtweg, F. F. Hennig, G. Schett, G. Welsch, Anti-citrullinated protein antibody positivity correlates with cartilage damage and proteoglycan levels in patients with rheumatoid arthritis in the hand joints. Arthritis Rheumatol 66, 3283-3288 (2014).

26. J. Sokolove, X. Zhao, P. E. Chandra, W. H. Robinson, Immune complexes containing citrullinated fibrinogen costimulate macrophages via Toll-like receptor 4 and Fcgamma receptor. Arthritis Rheum 63, 53-62 (2011).

27. A. Kleyer, S. Finzel, J. Rech, B. Manger, M. Krieter, F. Faustini, E. Araujo, A. J. Hueber, U. Harre, K. Engelke, G. Schett, Bone loss before the clinical onset of rheumatoid arthritis in subjects with anticitrullinated protein antibodies. Ann Rheum Dis 73, 854-860 (2014).

28. L. A. Trouw, E. M. Haisma, E. W. Levarht, D. van der Woude, A. Ioan-Facsinay, M. R. Daha, T. W. Huizinga, R. E. Toes, Anti-cyclic citrullinated peptide antibodies from rheumatoid arthritis patients activate complement via both the classical and alternative pathways. Arthritis Rheum 60, 1923-1931 (2009).

29. L. Laurent, C. Clavel, O. Lemaire, F. Anquetil, M. Cornillet, L. Zabraniecki, L. Nogueira, B. Fournie, G. Serre, M. Sebbag, Fcgamma receptor profile of monocytes and macrophages from rheumatoid arthritis patients and their response to immune complexes formed with autoantibodies to citrullinated proteins. Ann Rheum Dis 70, 1052-1059 (2011).

30. R. Khandpur, C. Carmona-Rivera, A. Vivekanandan-Giri, A. Gizinski, S. Yalavarthi, J. S. Knight, S. Friday, S. Li, R. M. Patel, V. Subramanian, P. Thompson, P. Chen, D. A. Fox, S. Pennathur, M. J. Kaplan, NETs are a source of citrullinated autoantigens and stimulate inflammatory responses in rheumatoid arthritis. Sci Transl Med 5, 178ra140 (2013).

31. H. Leyendeckers, M. Odendahl, A. Lohndorf, J. Irsch, M. Spangfort, S. Miltenyi, N. Hunzelmann, M. Assenmacher, A. Radbruch, J. Schmitz, Correlation analysis between frequencies of circulating antigen-specific IgG-bearing memory B cells and serum titers of antigen-specific IgG. Eur J Immunol 29, 1406-1417 (1999).

32. K. L. Good-Jacobson, E. Song, S. Anderson, A. H. Sharpe, M. J. Shlomchik, CD80 expression on $\mathrm{B}$ cells regulates murine $\mathrm{T}$ follicular helper development, germinal center $\mathrm{B}$ cell survival, and plasma cell generation. J Immunol 188, 4217-4225 (2012).

33. H. Niu, G. Cattoretti, R. Dalla-Favera, BCL6 controls the expression of the B7-1/CD80 costimulatory receptor in germinal center B cells. $J$ Exp Med 198, 211-221 (2003).

34. R. D. Vergroesen, L. M. Slot, L. Hafkenscheid, M. T. Koning, E. I. H. van der Voort, C. A. Grooff, G. Zervakis, H. Veelken, T. W. J. Huizinga, T. Rispens, H. U. Scherer, R. E. M. Toes, B-cell receptor sequencing of anti-citrullinated protein antibody (ACPA) IgGexpressing $\mathrm{B}$ cells indicates a selective advantage for the introduction of $\mathrm{N}$-glycosylation sites during somatic hypermutation. Ann Rheum Dis 77, 956-958 (2018).

35. S. Sato, N. Ono, D. A. Steeber, D. S. Pisetsky, T. F. Tedder, CD19 regulates B lymphocyte signaling thresholds critical for the development of B-1 lineage cells and autoimmunity. $J$ Immunol 157, 4371-4378 (1996).

36. M. Inaoki, S. Sato, B. C. Weintraub, C. C. Goodnow, T. F. Tedder, CD19-regulated signaling thresholds control peripheral tolerance and autoantibody production in B lymphocytes. J Exp Med 186, 1923-1931 (1997). 
37. T. Yuasa, S. Kubo, T. Yoshino, A. Ujike, K. Matsumura, M. Ono, J. V. Ravetch, T. Takai, Deletion of fcgamma receptor IIB renders H-2(b) mice susceptible to collagen-induced arthritis. J Exp Med 189, 187-194 (1999).

38. X. Zhang, E. Burch, L. Cai, E. So, F. Hubbard, E. L. Matteson, S. E. Strome, CD40 mediates downregulation of $\mathrm{CD} 32 \mathrm{~B}$ on specific memory B cell populations in rheumatoid arthritis. J Immunol 190, 6015-6022 (2013).

39. S. K. O'Neill, Y. X. Cao, K. M. Hamel, P. D. Doodes, G. Hutas, A. Finnegan, Expression of CD80/86 on B cells is essential for autoreactive $\mathrm{T}$ cell activation and the development of arthritis. Journal of Immunology 179, 5109-5116 (2007).

40. P. P. Tak, M. E. Doorenspleet, M. J. H. de Hair, P. L. Klarenbeek, M. H. van Beers-Tas, A. H. C. van Kampen, D. van Schaardenburg, D. M. Gerlag, F. Baas, N. de Vries, Dominant B cell receptor clones in peripheral blood predict onset of arthritis in individuals at risk for rheumatoid arthritis. Ann Rheum Dis 76, 1924-1930 (2017).

41. G. Schett, P. Emery, Y. Tanaka, G. Burmester, D. S. Pisetsky, E. Naredo, B. Fautrel, R. van Vollenhoven, Tapering biologic and conventional DMARD therapy in rheumatoid arthritis: current evidence and future directions. Ann Rheum Dis 75, 1428-1437 (2016).

42. H. W. van Steenbergen, D. Aletaha, L. J. Beaart-van de Voorde, E. Brouwer, C. Codreanu, B. Combe, J. E. Fonseca, M. L. Hetland, F. Humby, T. K. Kvien, K. Niedermann, L. Nuno, S. Oliver, S. Rantapaa-Dahlqvist, K. Raza, D. van Schaardenburg, G. Schett, L. De Smet, G. Szucs, J. Vencovsky, P. Wiland, M. de Wit, R. L. Landewe, A. H. van der Helm-van Mil, EULAR definition of arthralgia suspicious for progression to rheumatoid arthritis. Ann Rheum Dis 76, 491-496 (2017).

43. H. W. van Steenbergen, L. Mangnus, M. Reijnierse, T. W. Huizinga, A. H. van der Helmvan Mil, Clinical factors, anticitrullinated peptide antibodies and MRI-detected subclinical inflammation in relation to progression from clinically suspect arthralgia to arthritis. Ann Rheum Dis 75, 1824-1830 (2016).

44. D. B. Kuhns, D. A. L. Priel, J. Chu, K. A. Zarember, Isolation and Functional Analysis of Human Neutrophils. Curr Protoc Immunol 111, 1-16 (2015).

45. S. Picelli, O. R. Faridani, A. K. Bjorklund, G. Winberg, S. Sagasser, R. Sandberg, Fulllength RNA-seq from single cells using Smart-seq2. Nat Protoc 9, 171-181 (2014). 
Acknowledgments: We thank dr. Jan Wouter Drijfhout (LUMC, Leiden) for providing the CCP2 peptide. Vinculin $435-739$ was kindly provided by dr. Sander van Kasteren, Leiden Institute of Chemistry. Editorial services were provided by Nancy R. Gough (BioSerendipity, LLC, Elkridge, MD).

Funding: This work was supported by the Netherlands Organization for Scientific Research (NWO) (projects 435000033 and 91214031), the EU/EFPIA Innovative Medicines Initiative Joint Undertaking ((IMI-JU) BeTheCure grant (contract $\left.\mathrm{n}^{\circ} 1151422\right)$ and the IMI2-JU RTCure grant (contract $n^{\circ}$ 777357). HUS is the recipient of a NWO-ZonMW clinical fellowship (project 90714509), a NWO-ZonMW VENI grant (project 91617107), a ZonMW Enabling Technology Hotels grant (project 435002030) and received support from the Dutch Arthritis Foundation (projects 15-2-402 and 18-1-205). AHMvdH-vM received funding from the European Research Council (ERC) under the European Union's Horizon 2020 research and innovation programme (Starting grant, agreement No 714312). DLB is recipient of a NWO-ZonMW VICI grant and received funding from the ERC (Consolidator grant).

Author contributions: $\mathrm{HK}, \mathrm{EIHvdV}, \mathrm{NJB}, \mathrm{LMS}, \mathrm{AB}$ and $\mathrm{PFK}$ designed and performed experiments and analyzed and interpreted data; LEB, RMB and AHMvdH-vM provided samples and clinical data on individuals with arthralgia and interpreted data; HS and DLB provided technology and immortalized B cell clones; TWJH, REMT and HUS designed experiments and interpreted data; HK, REMT and HUS drafted the manuscript. All authors substantially revised the manuscript and approved the final submitted version.

Competing interests: DLB is currently an employee of UCB Pharma. HS is shareholder of AIMM Therapeutics, has received consulting fees from GSK and UniQure and holds a patent on the 
immortalization of B cells (patent title: Means and methods for influencing the stability of antibody producing cells; patent nr US10273454B2). The other authors declare no conflict of interests. Data and materials availability: All data associated with this study are in the paper or supplementary materials. The immortalized B cell lines were obtained using technology from AIMM Therapeutics and have been described previously (20); requests for these cell lines require written consent from the company AIMM. 


\section{Figures legends:}

Fig. 1. Identification and subset characterization of ACPA-positive and tetanus toxoid (TT)specific B cells in RA. (A) Gating strategy. Peripheral blood mononuclear cells (PBMCs) from single donors (RA patients, $\mathrm{n}=21$ ) were divided into three fractions and stained with either CCP2 and CArgP2 streptavidin tetramers to identify ACPA+ B cells or with directly labelled TT to identify TT + B cells. Pre-incubation with unlabeled TT or bovine serum albumin (BSA) was used to demonstrate specificity of the TT-staining. Subsets of B cells were delineated by the presence of CD20 and CD27. (B) Frequency of CD19+ B cells in PBMC and synovial fluid mononuclear cells (SFMCs) (upper panel). Frequency of TT + B cells and ACPA+ B cells in PBMCs versus ACPA+ B cells in SFMCs (lower panel). (C) Subset distribution of ACPA-, TT+, and ACPA+ B cells in PBMCs based on CD20 and CD27 abundance $(n=21)$. (D) Subset distribution of ACPA+ and ACPA-B cells in SFMCs $(\mathrm{n}=5)$. (E) Correlation between the frequency of ACPA+ memory B cells (defined as CD20+CD27+) in PBMC and plasma ACPA IgG concentrations (left panel, $\mathrm{n}=20$ ) and correlation between the frequency of TT + CD20+CD27+ B cells and plasma anti-TT IgG antibodies (right panel, $\mathrm{n}=10$ ). The correlation between ACPA + memory $\mathrm{B}$ cells and plasma ACPA IgG remains upon removal of the data point with the highest ACPA plasma concentration $(\mathrm{r}=0.57 ; \mathrm{p}=0.01)$. In $\mathrm{B}-\mathrm{E}$, each dot represents one patient sample. ${ }^{*} \mathrm{p} \leq 0.05,{ }^{*} \mathrm{p} \leq 0.01, * * *$

$\mathrm{p} \leq 0.001$, and $* * * * \mathrm{p} \leq 0.0001$. Two-tailed Mann-Whitney test in upper panel $\mathrm{B}$, one-way ANOVA with Dunn's multiple comparison test in lower panel B and in C and D); Pearson correlation in E. All data represent median $\pm 95 \%$ confidence interval $(\mathrm{CI}) ; \mathrm{n}=$ number of donors.

Fig. 2. Phenotypic characteristics of memory $(\mathrm{CD20}+\mathrm{CD27}+) \mathrm{ACPA}-, \mathrm{TT}+$, and ACPA+ B cells in RA patient-derived PBMCs. (A, B) Forward scatter (FSC) and proportion of memory B 
cells (MBCs) positive for activation markers (CD19, HLA-DR, CD80, CD86, and Ki-67) in the respective cell populations in PBMCs of individual donors in which both ACPA-positive and TTspecific B cells were assessed in parallel $(\mathrm{n}=19)$. Median fluorescence intensity (MFI) was analyzed for markers present in the entire cell population (FSC, CD19, HLA-DR). Subsets of cells were positive for CD80, CD86, and Ki-67. These data are depicted as percentage positive cells within the respective cell population (CD80, CD86, HLA-DR and Ki-67 were assessed in $n=8$ out of 19 donors). FSC data were compiled from samples that had not undergone permeabilization to avoid influencing cell size ( $\mathrm{n}=9$ out of 19$)$. Connected dots depict data from individual patients. (C) Correlation between clinical disease activity parameters and the characteristics of $\mathrm{ACPA}+\mathrm{B}$ cells $(n=20$; see fig. S4 for data on erythrocyte sedimentation rate $(E S R))$. Data are presented as percentage of ACPA+ memory B cells positive for the respective marker in relation to the disease activity score (DAS). The DAS was calculated based on 3 variables (3v: ESR and an evaluation of 44 joints for signs of pain (tender joint count) and swelling (swollen joint count) [DAS44(3v)]). The dotted lines represent the category of disease activity, with a score $>2.4$ being high disease activity, $>1.6$ and $<2.4$ being moderate disease activity, and $<1.6$ low disease activity or remission. $* \mathrm{p} \leq 0.05, * * \mathrm{p} \leq 0.01, * * * \mathrm{p} \leq 0.001$, and $* * * * \mathrm{p} \leq 0.0001$. Two-tailed Wilcoxon signed rank test in A for the FSC graph, one-way ANOVA with Dunn's multiple comparison test in A for the CD19 and HLA-DR graphs and B. $\mathrm{n}=$ number of donors.

Fig. 3. Comparison of the characteristics of ACPA-positive MBCs in different phases of disease. ACPA-positive MBCs were analyzed from patients with arthralgia $(n=8)$, recent onset, untreated RA $(n=7)$, and established, treated RA $(n=20)$ and compared to TT-specific B cells in the steady state (assessed in $n=13$ patients with established, treated $R A$ ) and in recently vaccinated 
RA patients $(\mathrm{n}=11)$. (A) The abundance and percent of cells positive for CD19, HLA-DR, CD80, CD86, or Ki-67 within the ACPA+ MBCs from the indicated RA disease stages. (B) The abundance and percent of cells positive for CD19, HLA-DR, CD80, CD86, or Ki-67 within the TT-specific MBCs from RA patients in the steady state $(n=13)$ and in patients upon recent vaccination (assessed within 30 days after booster immunization, $n=8$ out of 11). (C) Correlation of percent of Ki-67-positive, TT-specific MBCs with time after vaccination with TT in untreated RA patients (includes 3 patients assessed $>30$ days after booster immunization, $\mathrm{n}=11$ ). Every dot represents an individual patient, lines represent median values. ${ }^{*} \mathrm{p} \leq 0.05, * * \mathrm{p} \leq 0.01, * * * \mathrm{p} \leq$ 0.001 , and ${ }^{* * * *} \mathrm{p} \leq 0.0001$. One-way ANOVA with Dunn's multiple comparison test in A; twotailed Mann-Whitney test in B; Pearson correlation in $\mathrm{C} ; \mathrm{n}=$ number of donors.

Fig. 4. Presence of the inhibitory receptor CD32 on ACPA+ MBCs and TT-specific MBCs from patients with established RA. (A) Abundance of CD32 on the surface of ACPA+ or TTspecific MBCs ( $n=7)$. (B) Abundance of intracellular CD32 in ACPA+ or ACPA- MBCs $(n=4)$. Connected dots depict data from individual patient samples. $* \mathrm{p} \leq 0.05$. One-way ANOVA with Dunn's multiple comparison test in A, two-tailed Wilcoxon signed rank test in B; $n=$ number of donors.

Fig. 5. Functional properties of ACPA+B cells. (A) Cumulative secretion of IL-8, IL-6, or TNF $\alpha$ by PBMC-derived ACPA+ or ACPA- MBCs upon BCR and CD40 stimulation for 7 days $(n=5)$. (See fig. S8 for additional cytokine measurements). Equal numbers of ACPA+ and ACPA- B cells were cultured per donor. Results are shown as cytokine secretion per sorted cell. (B) Production of IL-8, IL-6, or TNF $\alpha$ by ACPA+ B cells from RA synovial fluid in the absence of ex vivo 
stimulation $(\mathrm{n}=4)$. SFMCs were cultured overnight in medium in the presence of $2 \mu \mathrm{g} / \mathrm{ml}$ brefeldin A to block release of the cytokines into the medium. Representative flow cytometry data (left) and collated results (right) are shown. To compare production, the difference between median fluorescence intensities of isotype staining and those of cytokine staining for the ACPA- and ACPA + B cells was plotted. (C) IL-8 secretion by an immortalized ACPA+ B cell clone upon stimulation with the indicated citrullinated proteins and irradiated CD40L-positive cells. Immortalized ACPA B cells were cultured with citrullinated (cit) fibrinogen (Fib), vinculin (Vin), or myelin basic protein (MBP) [white bars] or their mock-citrullinated counterparts [black bars] in the presence of irradiated CD40L-positive cells for 3 days (one representative experiment is shown out of $3 ; \mathrm{n}=3$ ). Supernatants were collected and tested for the presence of IL-8 by ELISA. (D) IL-8 secretion by the ACPA+ B cell clone and a TT-specific B cell clone upon stimulation with CCP2-avidin and soluble CD40L oligomers $(n=3, N=3)$. Results from one representative experiment are shown. (E) Neutrophil migration induced by supernatants from CCP2-stimulated ACPA + B cells . Healthy donor neutrophils were incubated for 90 minutes with supernatants from ACPA+ B cells stimulated with CCP2-tetramer for 3 days $(n=3, N=3)$. Results from one representative experiment are shown. ${ }^{*} \mathrm{p} \leq 0.05,{ }^{* *} \mathrm{p} \leq 0.01,{ }^{* * *} \mathrm{p} \leq 0.001, * * * * \mathrm{p} \leq 0.0001$. Two-tailed, unpaired student's $t$ test in C; two-tailed paired t test in (E). In A-B, $n=$ number of donors. In C-E, data represent mean $\pm \mathrm{SD}$ from one representative experiment of three experiments $(\mathrm{N}=3)$ with 3 technical replicates $(\mathrm{n}=3)$. 
Table 1. Characteristics of patients with ACPA-positive arthralgia and established RA included in the study

\section{At-Risk Arthralgia Established RA}

\begin{tabular}{lcc}
\hline Number of patients & 8 & 20 \\
ACPA-IgG plasma & & \\
concentrations & & \\
$\quad$ Median (AU/ml) & 420 & 2343 \\
$\quad$ Range (AU/ml) & $31-2563$ & $101-7667$ \\
$\begin{array}{l}\text { Frequency of ACPA-positive B } \\
\text { cells in total PBMCs }\end{array}$ & & \\
$\quad$ Median (\%) & 0.0017 & 0.0049 \\
$\quad$ Range (\%) & $0.0008-0.0388$ & $0.0012-0.0237$ \\
\hline
\end{tabular}

Table 2. List of primers used for real-time PCR of isolated B cell populations

\begin{tabular}{|l|l|l|}
\hline Gene & Forward & Reverse \\
\hline$B 2 M$ & 5' GATCGAGACATGTAAGCAGC '3 & 5' TCAAACATGGAGACAGCAC '3 \\
\hline$C D 19$ & 5' TGGAGACGGGTCTGTTGTTG '3 & 5' CAGCAGCCAGTGCCATAGTA '3 \\
\hline$C D 20$ & 5' CGTGCTCCAGACCCAAATCT '3 & 5' TCAGTTAGCCCAACCACTTCT '3 \\
\hline$C D 80$ & 5' CATCACCATCCAAGTGTCCA '3 & 5' TGCCAGTAGATGCGAGTTTG '3 \\
\hline$C D 86$ & 5' GCTGTAACAGGGACTAGCACA '3 & 5' CTTAGGTTCTGGGTAACCGTGT '3 \\
\hline
\end{tabular}



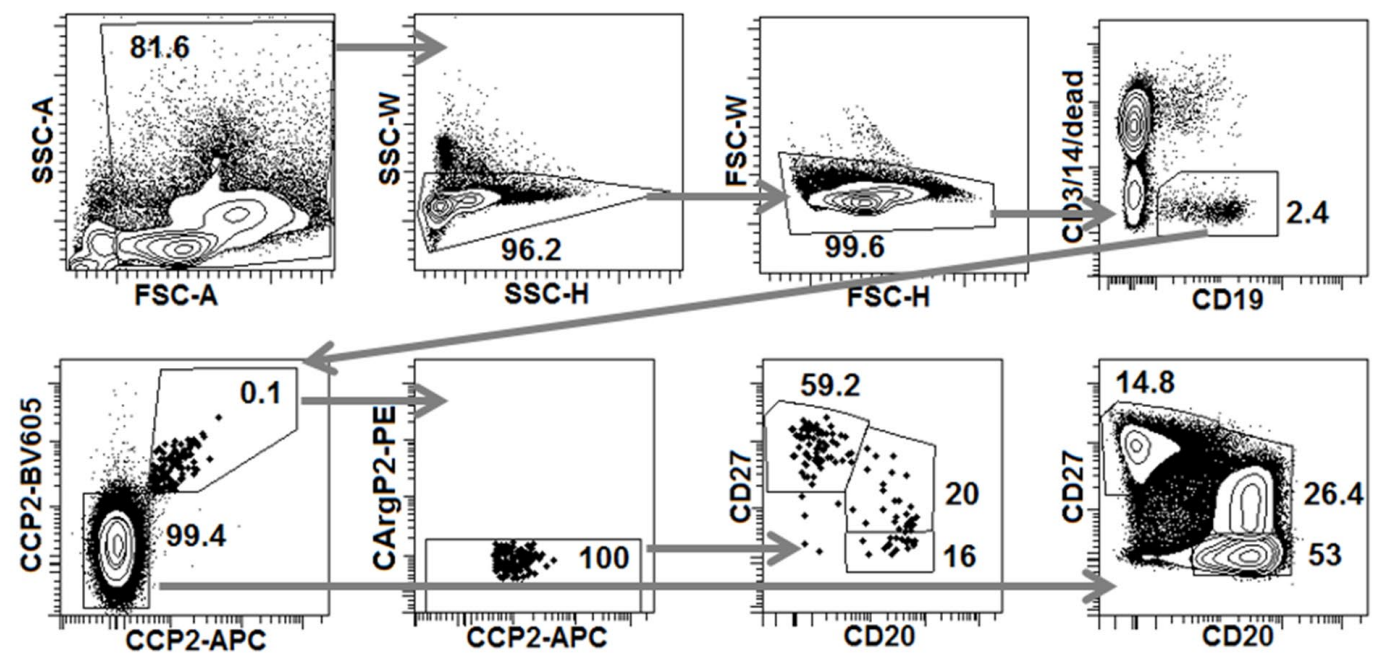

Fig. S1. Subsets of ACPA-positive B cells in synovial fluid of inflamed joints from patients with RA. Gating strategy for the identification and subset characterization of ACPA-positive B cells. ACPA-positive B cells were identified using differentially labelled CCP2 and CArgP2 streptavidin tetramers. B cell subsets were delineated based on the differential abundance of CD20 and CD27.
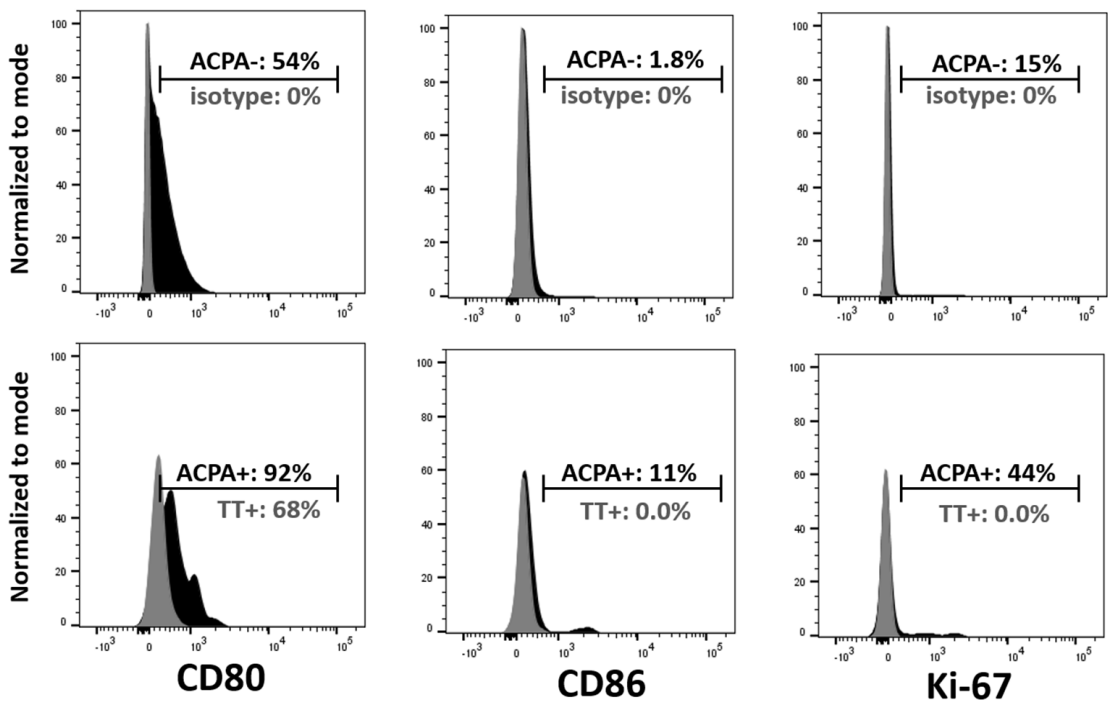

Fig. S2. Histogram plots depicting the positivity for CD80, CD86, or Ki-67 in ACPA-positive (ACPA+), tetanus toxoid-specific (TT+), and bulk (ACPA-) MBC populations. Data depict results from one representative donor (for combined data see Figure 2B). 


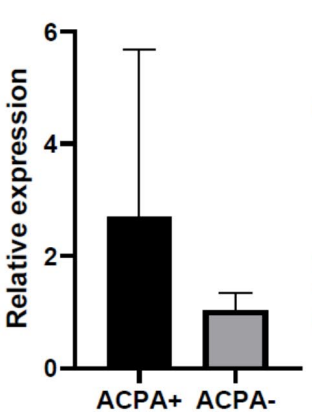

CD19

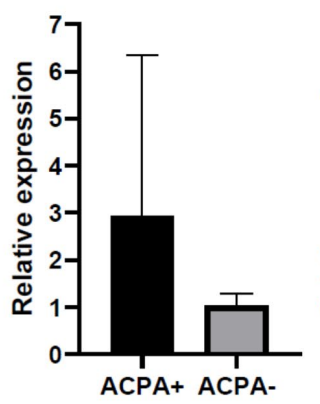

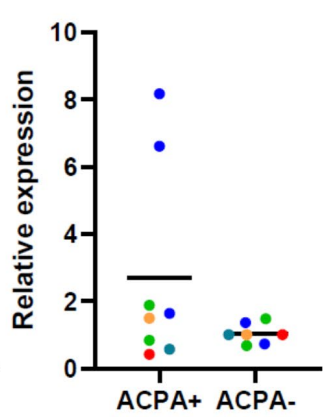

CD19

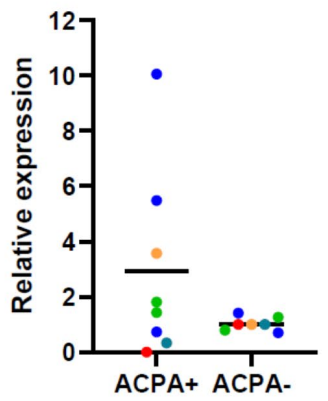

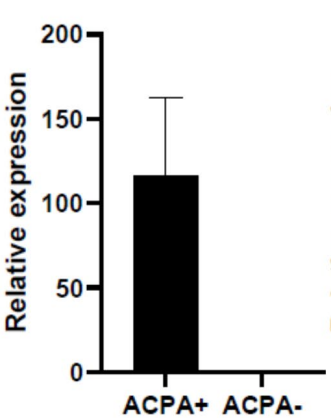

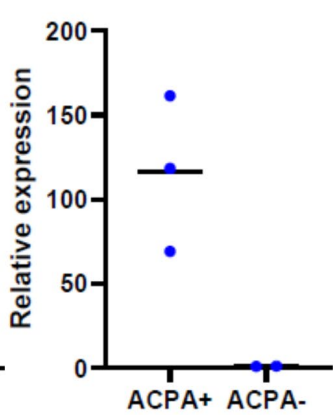

CD86

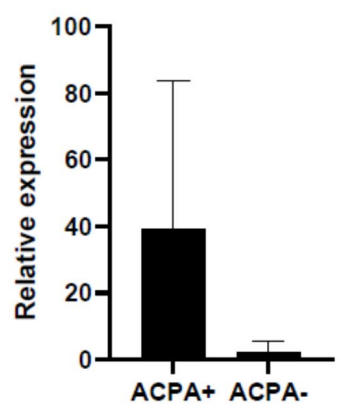

CD86

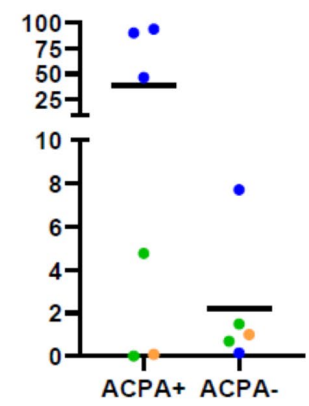

Fig. S3. Relative gene expression of $B$ cell phenotypic markers in ACPA-positive and non-citrulline-reactive MBCs. Transcript abundance was determined by RT-PCR using mRNA derived from ACPA-positive (ACPA+) B cells and non-citrulline reactive (ACPA-) B cells. Each dot corresponds to a pool of $8-30$ cells, colors represent individual patients $(n=5)$. Expression is presented relative to the expression in the ACPA-samples and corrected for the expression of beta-2 microglobulin (B2M) within donors. ACPA+ cells $[\mathrm{CD} 19+\mathrm{CD} 20+\mathrm{CD} 27+(\mathrm{CCP} 2+$ or $\mathrm{CArgP} 2+)]$ and $\mathrm{ACPA}-$ cells $[\mathrm{CD} 19+\mathrm{CD} 20+\mathrm{CD} 27+(\mathrm{CCP} 2-$ or $\mathrm{CArgP} 2-)]$ were obtained by FACS from patients with ACPA-positive RA.

CD80

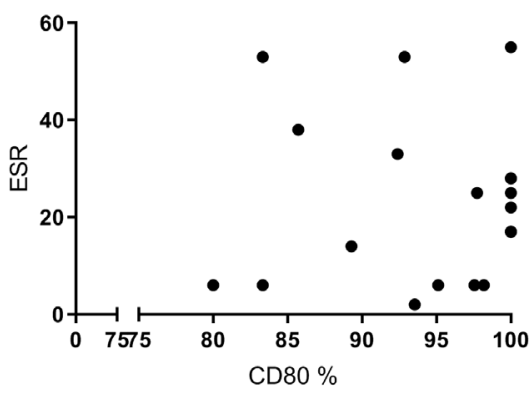

CD86

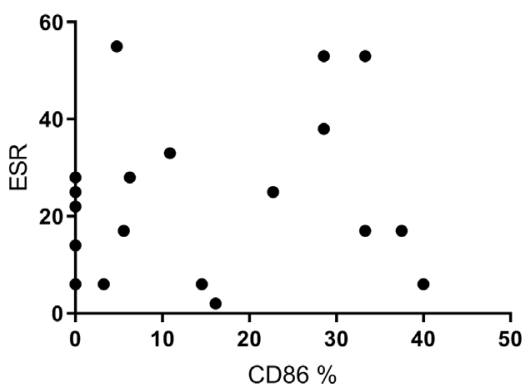

Ki-67

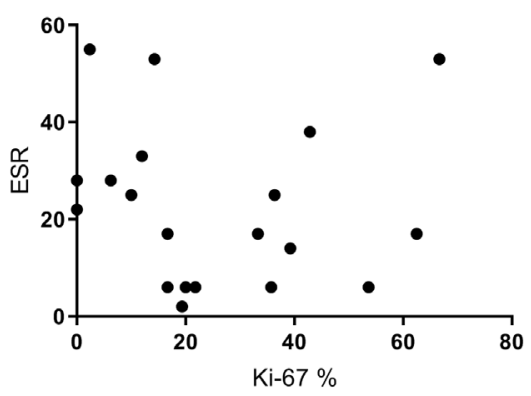

Fig. S4. Correlation analysis between systemic inflammation and the characteristics of ACPA-positive MBCs. Data are presented as percentage of ACPA-positive MBCs that are also positive for the indicated marker in relation to the erythrocyte sedimentation rate $(\mathrm{ESR})(\mathrm{n}=20)$. 
A
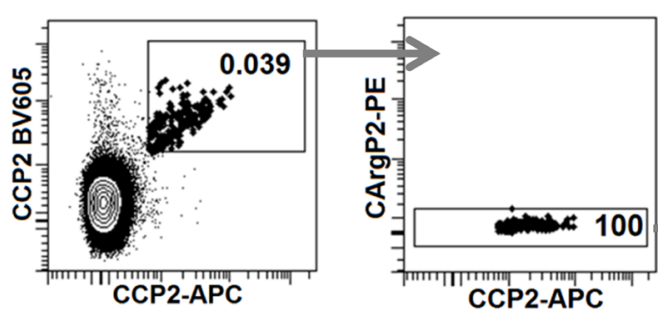

CCP2-APC

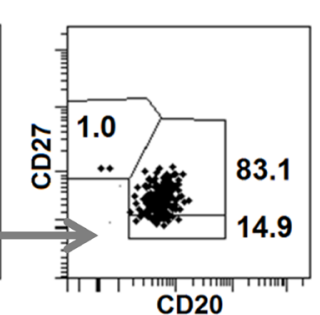

B

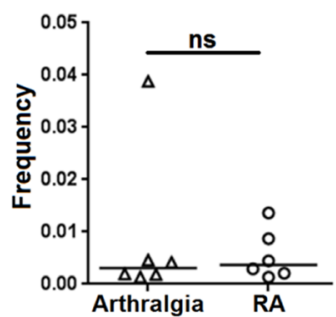

C

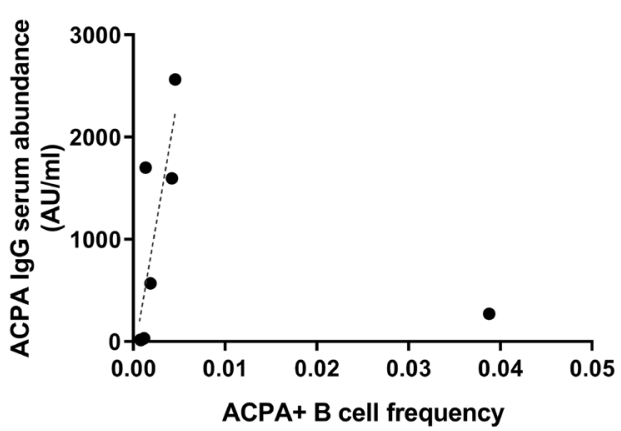

Subsets of ACPA-expressing B cells

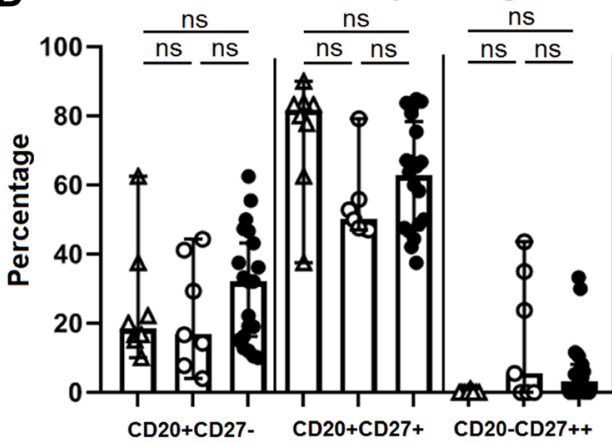

$\Delta \quad$ ACPA+ B cells, arthralgia

- $A C P A+B$ cells, recent onset RA

- $A C P A+B$ cells, established RA

Fig. S5. Characteristics of ACPA-positive B cells in individuals with ACPA+ arthralgia. (A) ACPA-positive $\mathrm{B}$ cells in individuals with arthralgia in PBMCs. (B) Frequency of ACPA-positive B cells in PBMCs from individuals with arthralgia compared to the frequency in RA patients with matched ACPA IgG plasma abundance (available for $\mathrm{n}=6$ ). (C) Correlation between the frequency of ACPA-positive B cells in PBMCs from individuals with arthralgia and serum ACPA IgG abundance $(n=8)$. The dotted line depicts the correlation if the one outlying donor with a high frequency of ACPA-positive B cells is removed from the analysis (Pearson R 0.81, P 0.02) (D) $B$ cell subsets identified by the abundance of CD20 and CD27 on ACPA-positive B cells from individuals with arthralgia $(n=8)$, patients with early onset, untreated RA $(n=7)$, and patients with established, treated RA $(n=$ 20). ns, non-significant $P>0.05$. Two-tailed Mann-Whitney test in B; Pearson correlation in C; one-way ANOVA with Dunn's multiple comparison test in D. $(\mathrm{n}=$ number of donors $)$

CD80

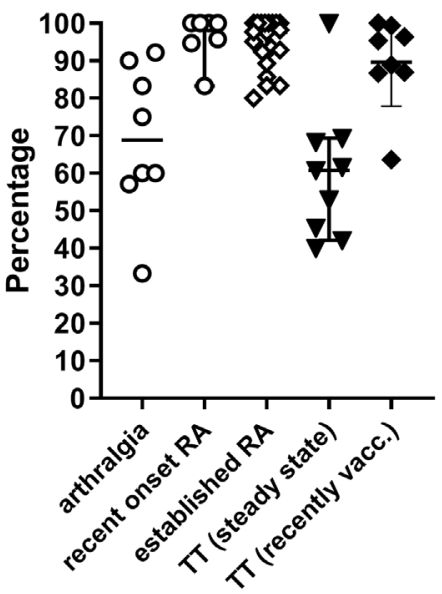

$\mathrm{Ki}-67$

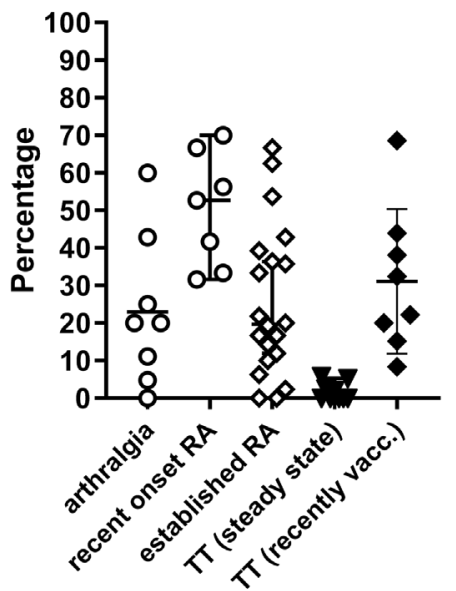

Fig. S6. Phenotype of ACPA-positive B cells in different disease phases compared to TT-specific B cells in the steady state and upon recent vaccination in patients with RA. ACPA-positive B cells (open symbols), TT specific B cells (closed symbols). Recently vaccinated (recently vacc.) indicates analysis 28 days after booster injection. 
CD80 expression on TT-specific MBC

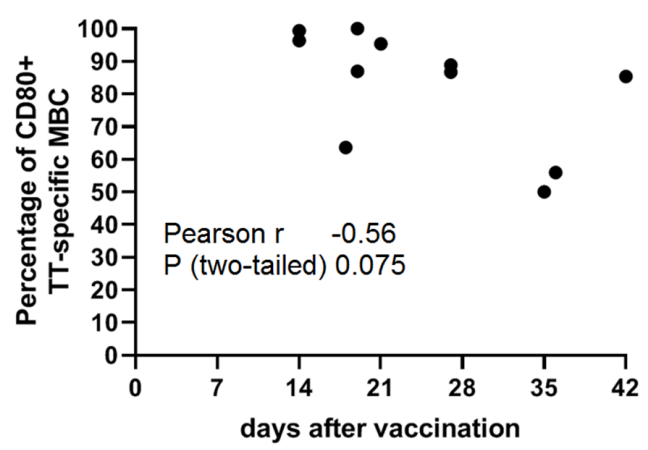

Relative CD19 expression on TT-specific MBC

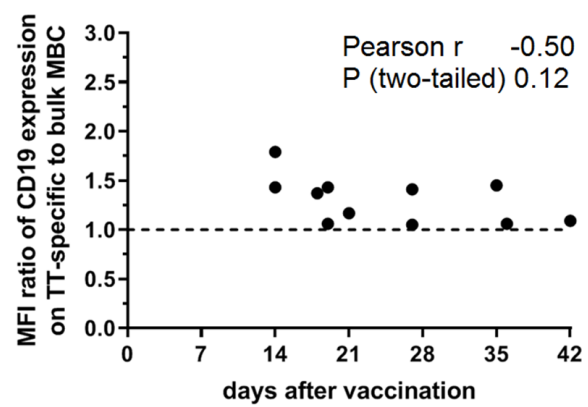

CD86 expression on TT-specific MBC

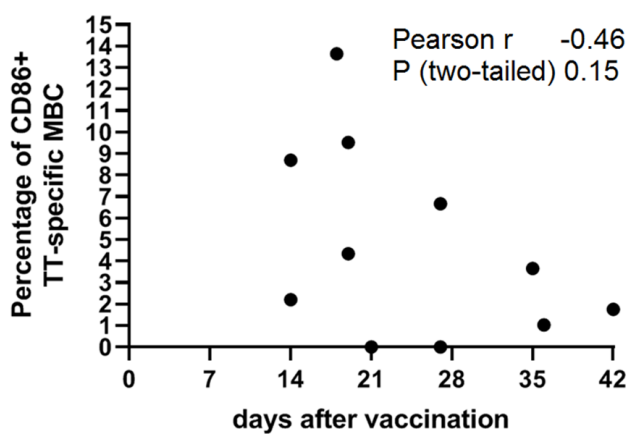

Relative HLA-DR expression on TT-specific MBC

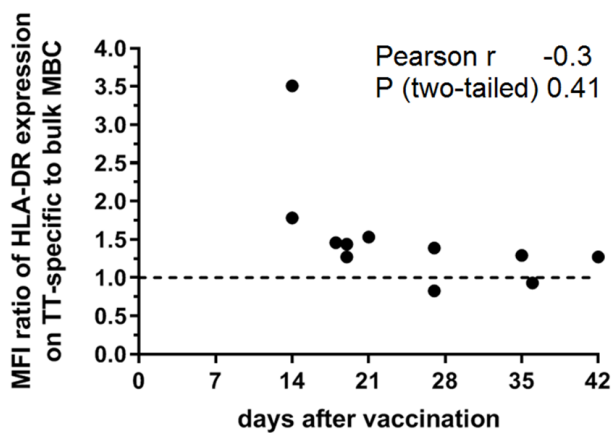

Fig. S7. Correlation between the proportion of TT-specific MBCs positive for CD80 or CD86, and abundance of CD19 or HLA-DR and time after TT vaccination in untreated RA patients. $(\mathrm{n}=11)$

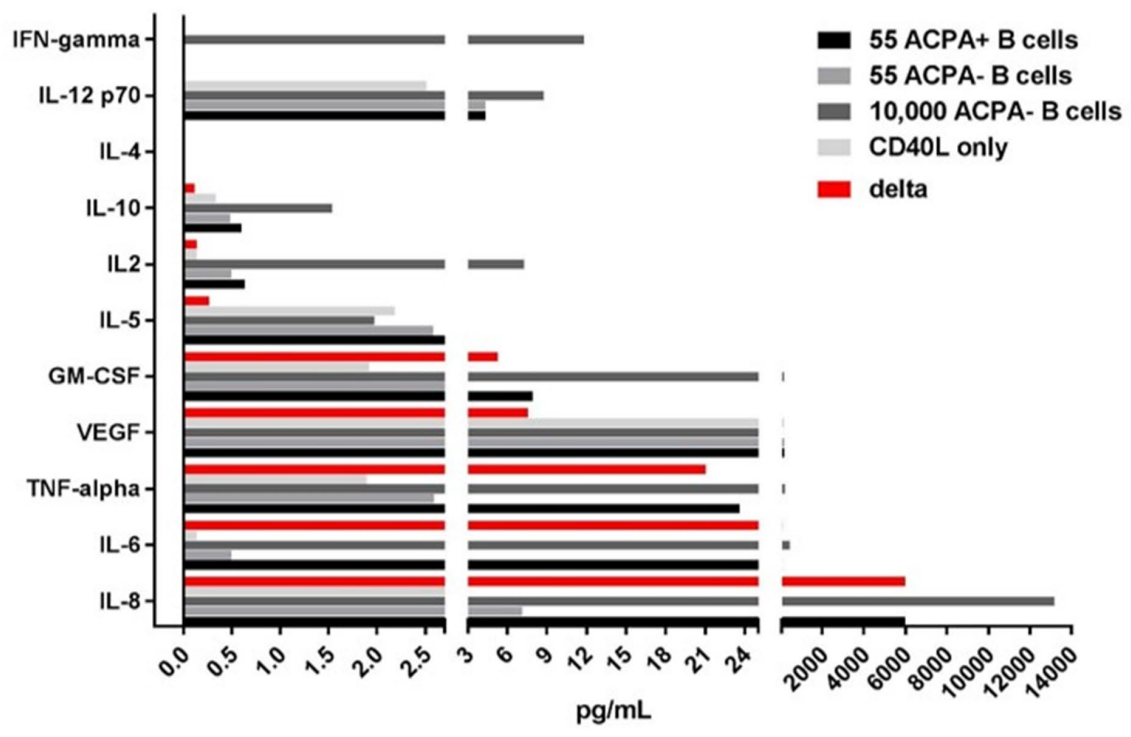

Fig. S8. Cytokine secretion by ACPA-positive MBCs. Representative graph of 11 cytokines secreted by sorted, CD20+CD27+ ACPA-positive and ACPA-negative B cells after 7 days of CD40 and BCR stimulation. Cytokines are ranked from bottom to top based on the difference in secretion between ACPA-positive and ACPA-negative $\mathrm{B}$ cells (red, delta). As a positive control, 10,000 CD20+CD27+ ACPA-negative B cells were treated with the same stimulants (dark grey). As a negative control, irradiated CD40L-positive cells were treated with antiIgG/IgM Fab2 fragments in the absence of B cells (light grey). 


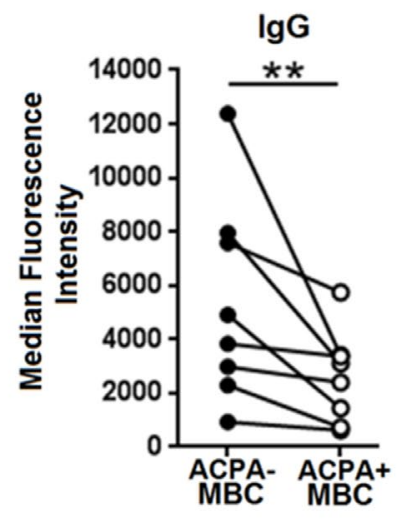

Fig. S9. Abundance of IgG on CD20+CD27+ ACPA-positive and ACPA-negative B cells from RA patient peripheral blood. Each dot represents an individual donor $(n=8)$. Connected dots depict data from individual patient samples. ${ }^{* *} \mathrm{p} \leq 0.01$. Two-tailed Wilcoxon signed rank test.

A
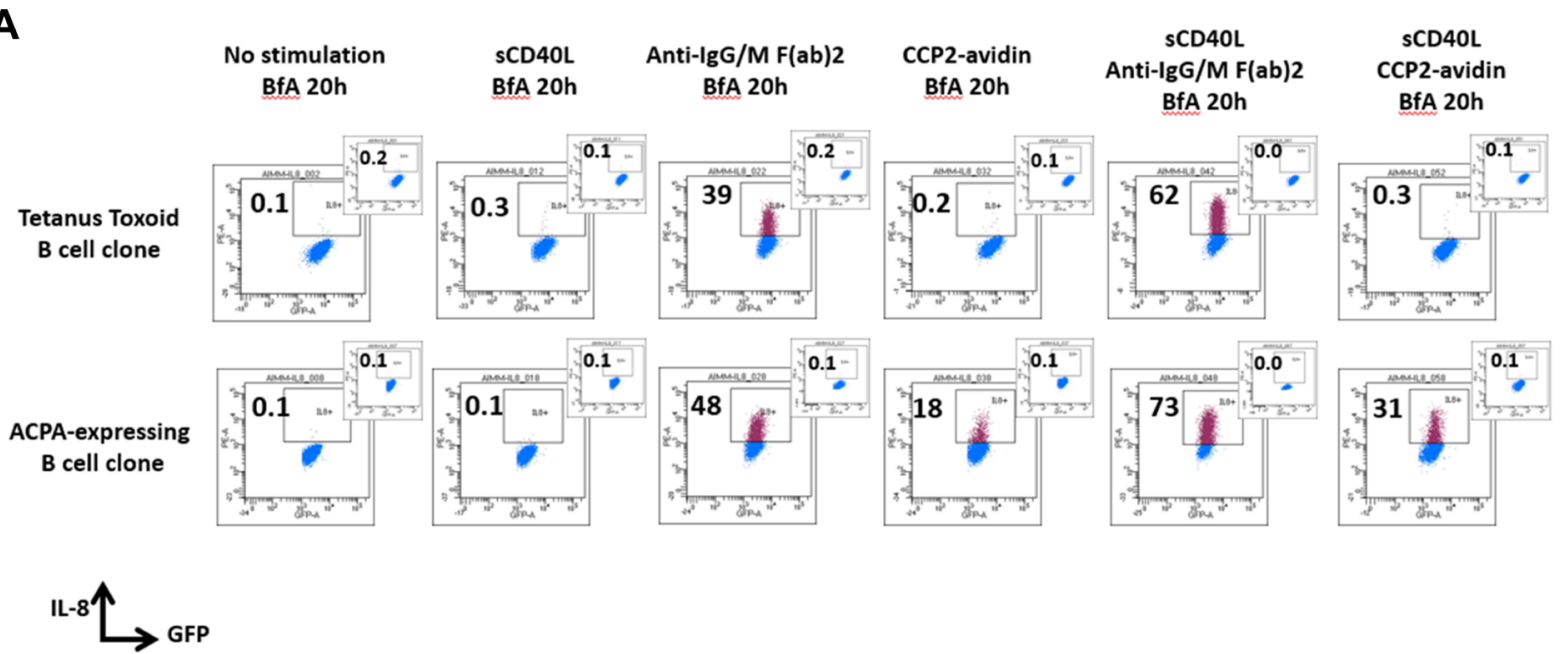

B

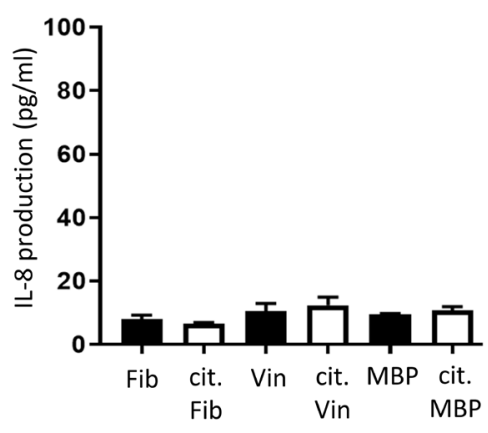

Fig. S10. Production of IL-8 by TT-specific and ACPA-positive, immortalized B cell clones triggered by various stimulants. (A) Data obtained by flow cytometry. Transduced cells are visualized by the expression of GFP. Data are representative of 1 of 3 experiments. Large graph shows staining with anti-IL-8 PE; small popout indicates isotype control staining for IL-8. (B) Data obtained by ELISA upon stimulation of the TT-specific B cell clone with different citrullinated proteins or their native variants. 
A
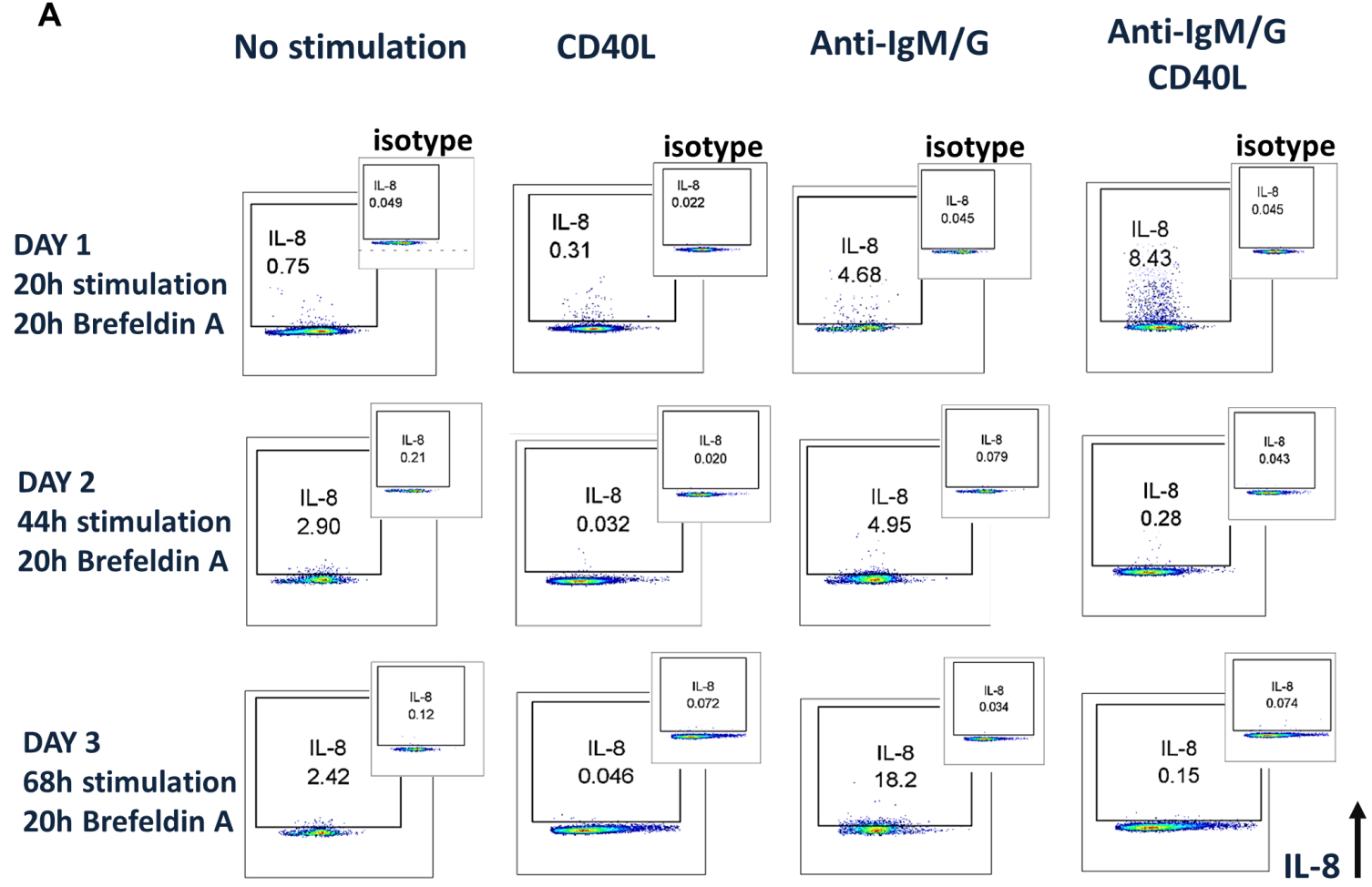

B IL-8 secretion by B cells

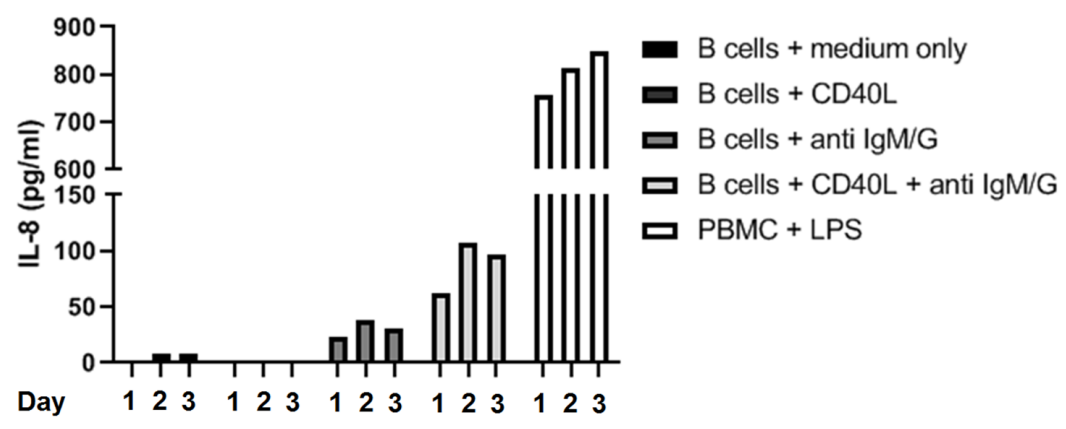

Fig. S11. Production of IL-8 by B cells from healthy individuals upon different stimulation conditions and at different time points after stimulation. (A) Data obtained by flow cytometry. Data are representative of 1 of 3 experiments. Large graph shows staining with anti-IL-8 PE; small popout indicates isotype controle stainings. (B) ELISA analysis of IL-8 secretion by the indicated cells stimulated as indicated. Supernatant was collected on day 1, day 2, and day 3 after stimulation. LPS, lipopolysaccharide 
Data S1. Subject-level data for experiments with $n<20$ donors/replicates.

Figure 2A.

\begin{tabular}{|l|l|r|r|}
\hline No & \multirow{2}{*}{$\begin{array}{c}\text { Patient } \\
\text { code }\end{array}$} & \multicolumn{2}{|c|}{$\begin{array}{c}\text { FSC } \\
\text { (ratio to ACPA- MBC) }\end{array}$} \\
\cline { 3 - 4 } & & $\begin{array}{c}\text { TT+ } \\
\text { MBC }\end{array}$ & $\begin{array}{c}\text { ACPA+ } \\
\text { MBC }\end{array}$ \\
\hline 1 & RL0573 & 0,94 & 1,08 \\
\hline 2 & RL0745 & 1,11 & 1,18 \\
\hline 3 & RL1115 & 0,89 & 0,94 \\
\hline 4 & RL1140 & 0,90 & 1,15 \\
\hline 5 & RL1141 & 0,94 & 1,11 \\
\hline 6 & RL1190 & 0,96 & 1,03 \\
\hline 7 & RL1199 & 1,03 & 1,03 \\
\hline 8 & RL1200 & 1,06 & 1,05 \\
\hline 9 & RL1201 & 1,00 & 1,10 \\
\hline
\end{tabular}

\begin{tabular}{|l|l|r|r|r|r|r|r|}
\hline \multirow{2}{*}{ No } & \multirow{2}{*}{$\begin{array}{c}\text { Patient } \\
\text { code }\end{array}$} & \multicolumn{3}{|c|}{$\begin{array}{c}\text { CD19 } \\
\text { (MFI) }\end{array}$} & \multicolumn{3}{|c|}{$\begin{array}{c}\text { HLA-DR } \\
\text { (MFI) }\end{array}$} \\
\cline { 3 - 8 } & & $\begin{array}{c}\text { ACPA- } \\
\text { MBC }\end{array}$ & $\begin{array}{c}\text { TT+ } \\
\text { MBC }\end{array}$ & $\begin{array}{c}\text { ACPA+ } \\
\text { MBC }\end{array}$ & $\begin{array}{c}\text { ACPA- } \\
\text { MBC }\end{array}$ & $\begin{array}{c}\text { TT+ } \\
\text { MBC }\end{array}$ & $\begin{array}{c}\text { ACPA+ } \\
\text { MBC }\end{array}$ \\
\hline 1 & RL0488 & 380 & 432 & & & & \\
\hline 2 & RL0489 & 339 & 438 & 714 & 342 & 358 & 1748 \\
\hline 3 & RL0493 & 417 & 483 & 556 & 352 & 463 & 662 \\
\hline 4 & RL0494 & 385 & 311 & 482 & 268 & 321 & 449 \\
\hline 5 & RL0495 & 371 & 402 & 585 & 219 & 230 & 366 \\
\hline 6 & RL0549 & 600 & 438 & 789 & 527 & 681 & 1333 \\
\hline 7 & RL0550 & 497 & 442 & 818 & 376 & 317 & 358 \\
\hline 8 & RL0551 & 490 & 478 & 1095 & 644 & 666 & 720 \\
\hline 9 & RL0552 & 508 & 463 & 832 & 814 & 596 & 1209 \\
\hline 10 & RL0541 & 529 & 402 & 767 & nd & nd & nd \\
\hline 11 & RL0573 & 526 & 629 & 811 & nd & nd & nd \\
\hline 12 & RL0745 & 471 & 529 & 753 & nd & nd & nd \\
\hline 13 & RL1115 & 413 & 466 & 588 & nd & nd & nd \\
\hline
\end{tabular}

nd $=$ no data 
Figure 2B.

\begin{tabular}{|l|l|r|r|r|r|r|r|r|r|r|}
\hline No & $\begin{array}{l}\text { Patient } \\
\text { code }\end{array}$ & \multicolumn{3}{|c|}{$\begin{array}{c}\text { CD80 } \\
(\%)\end{array}$} & \multicolumn{3}{c|}{$\begin{array}{c}\text { CD86 } \\
(\%)\end{array}$} & \multicolumn{3}{c|}{$\begin{array}{c}\text { Ki-67 } \\
\text { (\%) }\end{array}$} \\
\cline { 3 - 12 } & & $\begin{array}{c}\text { ACPA- } \\
\text { MBC }\end{array}$ & $\begin{array}{c}\text { TT+ } \\
\text { MBC }\end{array}$ & $\begin{array}{c}\text { ACPA+ } \\
\text { MBC }\end{array}$ & $\begin{array}{c}\text { ACPA- } \\
\text { MBC }\end{array}$ & $\begin{array}{c}\text { TT+ } \\
\text { MBC }\end{array}$ & $\begin{array}{c}\text { ACPA+ } \\
\text { MBC }\end{array}$ & $\begin{array}{c}\text { ACPA- } \\
\text { MBC }\end{array}$ & $\begin{array}{c}\text { TT+ } \\
\text { MBC }\end{array}$ & $\begin{array}{c}\text { ACPA+ } \\
\text { MBC }\end{array}$ \\
\hline 1 & RL0489 & 49,15 & 42,11 & 83,33 & 4,77 & 0,00 & 33,33 & 7,24 & 5,26 & 66,67 \\
\hline 2 & RL0493 & 53,52 & 69,35 & 97,73 & 1,76 & 1,61 & 22,73 & 14,65 & 0,00 & 36,36 \\
\hline 3 & RL0494 & 51,74 & 52,94 & 80,00 & 3,84 & 0,00 & 40,00 & 3,37 & 5,88 & 20,00 \\
\hline 4 & RL0495 & 59,24 & 68,33 & 92,39 & 5,09 & 0,00 & 10,87 & 7,58 & 0,00 & 11,96 \\
\hline 5 & RL0549 & 73,37 & 100,00 & 85,71 & 14,06 & 12,50 & 28,57 & 9,33 & 0,00 & 42,86 \\
\hline 6 & RL0550 & 59,93 & 61,62 & 97,56 & 2,15 & 0,54 & 3,25 & 5,67 & 2,16 & 35,77 \\
\hline 7 & RL0551 & 41,90 & 40,00 & 89,29 & 1,24 & 0,00 & 0,00 & 6,15 & 0,00 & 39,29 \\
\hline 8 & RL0552 & 43,01 & 60,76 & 83,33 & 2,27 & 1,27 & 0,00 & 6,28 & 2,53 & 16,67 \\
\hline
\end{tabular}

Figure 2C, Figure 3A (ACPA+ MBC, established RA), Fig. S4.

\begin{tabular}{|c|c|c|c|c|c|c|c|c|c|c|}
\hline No & $\begin{array}{l}\text { Patient } \\
\text { code }\end{array}$ & $\begin{array}{c}\text { CD19 } \\
\text { (MFI ratio } \\
\text { to bulk } \\
\text { MBC) }\end{array}$ & $\begin{array}{c}\text { HLA-DR } \\
\text { (MFI ratio } \\
\text { to bulk } \\
\text { MBC) }\end{array}$ & $\begin{array}{c}\text { CD80 } \\
(\%)\end{array}$ & $\begin{array}{c}\text { CD86 } \\
(\%)\end{array}$ & $\begin{array}{c}\text { Ki-67 } \\
(\%)\end{array}$ & $\begin{array}{c}\text { DAS44 } \\
(3 v)\end{array}$ & $\begin{array}{c}\text { Tender } \\
\text { joint } \\
\text { count }\end{array}$ & $\begin{array}{l}\text { Swollen } \\
\text { joint count }\end{array}$ & $\begin{array}{c}\text { ESR } \\
(\mathrm{mm} / 1 \mathrm{~h})\end{array}$ \\
\hline 1 & RL0343 & 1,45 & 1,46 & 100,00 & 37,50 & 62,50 & 1,16 & 0 & 0 & 17 \\
\hline 2 & RL0346 & 1,88 & 0,71 & 100,00 & 33,33 & 33,33 & 2,05 & 2 & 2 & 17 \\
\hline 3 & RL0347 & 1,87 & 1,40 & 93,55 & 16,13 & 19,35 & nd & nd & nd & 2 \\
\hline 4 & RL0349 & 2,26 & 1,92 & 100,00 & 0,00 & 0,00 & 1,85 & 1 & 1 & 22 \\
\hline 5 & RL0351 & 1,73 & 1,43 & 100,00 & 0,00 & 0,00 & nd & nd & nd & 28 \\
\hline 6 & RL0367 & 1,50 & 1,28 & 100,00 & 6,25 & 6,25 & 2,79 & 4 & 6 & 28 \\
\hline 7 & RL0370 & 1,49 & 1,38 & 100,00 & 5,56 & 16,67 & nd & nd & nd & 17 \\
\hline 8 & RL0394 & 2,06 & 0,95 & 92,86 & 28,57 & 14,29 & nd & nd & nd & 53 \\
\hline 9 & RL0395 & 1,54 & 1,32 & 100,00 & 4,76 & 2,38 & 3,8 & 12 & 6 & 55 \\
\hline 10 & RL0396 & 1,45 & 1,37 & 98,18 & 14,55 & 21,82 & 0,82 & 0 & 0 & 6 \\
\hline 11 & RL0403 & 1,37 & 2,14 & 95,12 & 0,00 & 53,66 & nd & nd & nd & 6 \\
\hline 12 & RL0417 & 1,71 & 1,36 & 100,00 & 0,00 & 10,00 & 1,83 & 1 & 0 & 25 \\
\hline 13 & RL0489 & 2,11 & 5,11 & 83,33 & 33,33 & 66,67 & 3,74 & 13 & 4 & 53 \\
\hline 14 & RL0493 & 1,33 & 1,88 & 97,73 & 22,73 & 36,36 & nd & nd & nd & 25 \\
\hline 15 & RL0494 & 1,25 & 1,68 & 80,00 & 40,00 & 20,00 & 0,82 & 0 & 0 & 6 \\
\hline 16 & RL0495 & 1,58 & 1,67 & 92,39 & 10,87 & 11,96 & 1,44 & 0 & 1 & 33 \\
\hline 17 & RL0549 & 1,32 & 2,53 & 85,71 & 28,57 & 42,86 & 1,42 & 0 & 0 & 38 \\
\hline 18 & RL0550 & 1,65 & 0,95 & 97,56 & 3,25 & 35,77 & 3,04 & 17 & 0 & 6 \\
\hline 19 & RL0551 & 2,23 & 1,12 & 89,29 & 0,00 & 39,29 & 1,86 & 2 & 0 & 14 \\
\hline 20 & RL0552 & 1,64 & 1,49 & 83,33 & 0,00 & 16,67 & nd & nd & nd & 6 \\
\hline
\end{tabular}

nd, no data

bulk MBC, ACPA-negative MBC 
Figure 3A.

ACPA+ MBC, arthralgia

\begin{tabular}{|l|l|r|r|r|r|r|}
\hline No & Patient code & $\begin{array}{c}\text { CD19 } \\
\text { (MFI ratio to bulk MBC) }\end{array}$ & $\begin{array}{c}\text { HLA-DR } \\
\text { (MFI ratio to bulk MBC) }\end{array}$ & CD80 (\%) & CD86 (\%) & Ki-67 (\%) \\
\hline 1 & RL677 & 1,46 & 1,36 & 90,00 & 10,00 & 20,00 \\
\hline 2 & RL684 & 1,14 & 1,08 & 83,33 & 0,00 & 11,11 \\
\hline 3 & RL685 & 1,09 & 1,34 & 92,22 & 0,60 & 4,79 \\
\hline 4 & RL691 & 1,46 & 0,86 & 75,00 & 0,00 & 25,00 \\
\hline 5 & RL709 & 0,74 & 0,91 & 33,33 & 0,00 & 0,00 \\
\hline 6 & RL710 & 0,97 & 1,08 & 60,00 & 0,00 & 20,00 \\
\hline 7 & RL721 & 1,11 & 2,24 & 57,14 & 14,29 & 42,86 \\
\hline 8 & RL737 & 1,49 & 0,60 & 60,00 & 0,00 & 60,00 \\
\hline
\end{tabular}

bulk MBC, ACPA-negative MBC

ACPA+ MBC, recent onset RA

\begin{tabular}{|c|c|c|c|c|c|c|}
\hline No & Patient code & $\begin{array}{c}\text { CD19 } \\
\text { (MFI ratio to bulk MBC) }\end{array}$ & $\begin{array}{c}\text { HLA-DR } \\
\text { (MFI ratio to bulk MBC) }\end{array}$ & CD80 (\%) & CD86 (\%) & Ki-67 (\%) \\
\hline 1 & ASC003 & 1,49 & 2,41 & 100 & 44,44 & 66,67 \\
\hline 2 & ASC005 & 1,86 & 1,58 & 95,85 & 12,50 & 56,25 \\
\hline 3 & ASC006 & 1,40 & 2,32 & 100 & 0 & 33,33 \\
\hline 4 & ASC008 & 1,98 & 2,17 & 100 & 10,53 & 31,58 \\
\hline 5 & ASC009 & 1,87 & 2,07 & 94,74 & 21,05 & 52,63 \\
\hline 6 & ASC010 & 1,89 & 1,72 & 83,33 & 12,5 & 41,67 \\
\hline 7 & ASC012 & 1,36 & 3,17 & 100 & 50 & 70 \\
\hline
\end{tabular}

bulk MBC, ACPA-negative MBC

\section{Figure 3B.}

TT+ MBC, steady state

\begin{tabular}{|l|l|r|r|r|r|r|}
\hline No & Patient code & $\begin{array}{c}\text { CD19 } \\
\text { (MFI ratio to bulk MBC) }\end{array}$ & $\begin{array}{c}\text { HLA-DR } \\
\text { (MFI ratio to bulk MBC) }\end{array}$ & CD80 (\%) & CD86 (\%) & Ki-67 (\%) \\
\hline 1 & RL0488 & 1,14 & 1,02 & 45,45 & 3,6 & 0 \\
\hline 2 & RL0489 & 1,29 & 1,05 & 42,11 & 0,00 & 5,26 \\
\hline 3 & RL0493 & 1,16 & 1,32 & 69,35 & 1,61 & 0,00 \\
\hline 4 & RL0494 & 0,81 & 1,20 & 52,94 & 0,00 & 5,88 \\
\hline 5 & RL0495 & 1,08 & 1,05 & 68,33 & 0,00 & 0,00 \\
\hline 6 & RL0549 & 0,73 & 1,29 & 100,00 & 12,50 & 0,00 \\
\hline 7 & RL0550 & 0,89 & 0,84 & 61,62 & 0,54 & 2,16 \\
\hline 8 & RL0551 & 0,98 & 1,03 & 40,00 & 0,00 & 0,00 \\
\hline 9 & RL0552 & 0,91 & 0,73 & 60,76 & 1,27 & 2,53 \\
\hline 10 & RL0541 & 0,76 & nd & nd & nd & nd \\
\hline 11 & RL0573 & 1,20 & nd & nd & nd & nd \\
\hline 12 & RL0745 & 1,12 & nd & nd & nd & nd \\
\hline 13 & RL1115 & 1,13 & nd & nd & nd \\
\hline
\end{tabular}

nd $=$ no data

bulk MBC, ACPA-negative MBC 
TT + MBC, Recently vaccinated

\begin{tabular}{|c|c|c|c|c|c|c|}
\hline No & Patient code & $\begin{array}{c}\text { CD19 } \\
\text { (MFI ratio to bulk MBC) }\end{array}$ & $\begin{array}{c}\text { HLA-DR } \\
\text { (MFI ratio to bulk MBC) }\end{array}$ & CD80 (\%) & CD86 (\%) & Ki-67 (\%) \\
\hline 1 & ASC001 & 1,41 & 0,83 & 86,67 & 6,67 & 20,00 \\
\hline 2 & ASC002 & 1,43 & 1,44 & 100,00 & 9,52 & 38,10 \\
\hline 3 & ASC003 & 1,17 & 1,53 & 95,37 & 0,00 & 8,33 \\
\hline 4 & ASC004 & 1,05 & 1,39 & 88,89 & 0,00 & 22,22 \\
\hline 5 & ASC006 & 1,43 & 1,78 & 96,34 & 2,20 & 68,54 \\
\hline 6 & ASC007 & 1,06 & 1,27 & 86,96 & 4,35 & 15,22 \\
\hline 7 & ASC010 & 1,37 & 1,46 & 63,64 & 13,64 & 43,94 \\
\hline 8 & ASC011 & 1,79 & 3,51 & 99,41 & 8,70 & 32,46 \\
\hline
\end{tabular}

bulk MBC, ACPA-negative MBC

Figure 3C and Fig. S7.

\begin{tabular}{|c|c|c|c|c|c|c|c|}
\hline No & $\begin{array}{l}\text { Patient } \\
\text { code }\end{array}$ & $\begin{array}{l}\text { Days after booster tetanus } \\
\text { vaccination }\end{array}$ & $\begin{array}{c}\text { CD19 } \\
\text { (MFI ratio to } \\
\text { bulk MBC) }\end{array}$ & $\begin{array}{c}\text { HLA-DR } \\
\text { (MFI ratio to } \\
\text { bulk MBC) }\end{array}$ & $\begin{array}{c}\text { CD80 } \\
(\%)\end{array}$ & $\begin{array}{c}\text { CD86 } \\
(\%)\end{array}$ & $\begin{array}{c}\text { Ki-67 } \\
(\%)\end{array}$ \\
\hline 1 & ASC006 & 14 & 1,43 & 1,78 & 96,34 & 2,2 & 68,54 \\
\hline 2 & ASC011 & 14 & 1,79 & 3,51 & 99,41 & 8,7 & 32,46 \\
\hline 3 & ASC010 & 18 & 1,37 & 1,46 & 63,64 & 13,64 & 43,94 \\
\hline 4 & ASC002 & 19 & 1,43 & 1,44 & 100 & 9,52 & 38,1 \\
\hline 5 & ASC007 & 19 & 1,06 & 1,27 & 86,96 & 4,35 & 15,22 \\
\hline 6 & ASC003 & 21 & 1,17 & 1,53 & 95,37 & 0 & 8,33 \\
\hline 7 & ASC001 & 27 & 1,41 & 0,83 & 86,67 & 6,67 & 20 \\
\hline 8 & ASC004 & 27 & 1,05 & 1,39 & 88,89 & 0 & 22,22 \\
\hline 9 & ASC009 & 35 & 1,45 & 1,29 & 50 & 3,65 & 4,17 \\
\hline 10 & ASC008 & 36 & 1,06 & 0,93 & 55,93 & 1,03 & 1,8 \\
\hline 11 & ASC005 & 42 & 1,09 & 1,27 & 85,38 & 1,75 & 6,43 \\
\hline
\end{tabular}

bulk MBC, ACPA-negative MBC

Figure 4A.

\begin{tabular}{|l|r|r|r|r|}
\hline No & Patient code & ACPA- MBC (in MFI) & TT+ MBC (in MFI) & ACPA+ MBC (in MFI) \\
\hline 1 & RL0745 & 1094 & 1424 & 1056 \\
\hline 2 & RL1140 & 1619 & 1660 & 844 \\
\hline 3 & RL1141 & 1317 & 1961 & 5 \\
\hline 4 & RL1190 & 1674 & 2109 & 107 \\
\hline 5 & RL1199 & 1977 & 925 & 499 \\
\hline 6 & RL1200 & 1227 & 1817 & 227 \\
\hline 7 & RL1201 & 1713 & 3112 & 518 \\
\hline
\end{tabular}


Figure 4B.

\begin{tabular}{|l|r|r|r|}
\hline No & Patient code & ACPA- MBC (in MFI) & \multicolumn{1}{|c|}{ ACPA+ MBC (in MFI) } \\
\hline 1 & RL1537 & 159 & 82 \\
\hline 2 & RL1538 & 132 & 8 \\
\hline 3 & RL1539 & 107 & -64 \\
\hline 4 & RL1540 & 59 & 15 \\
\hline
\end{tabular}

Figure 5A.

\begin{tabular}{|l|l|c|c|r|r|r|r|}
\hline \multirow{2}{*}{ No } & \multirow{2}{*}{ Patient code } & \multicolumn{3}{|c|}{ ACPA- MBC } & \multicolumn{3}{c|}{ ACPA+ MBC } \\
\cline { 3 - 8 } & & IL-8 & IL-6 & TNFa & IL-8 & \multicolumn{1}{c|}{ IL-6 } & \multicolumn{1}{c|}{ TNFa } \\
\hline 1 & RL643 & 0,25 & 0,03 & 0,12 & 1,63 & 0,03 & 0,12 \\
\hline 2 & RL648 & 0,87 & 0,10 & 0,22 & 11,81 & 0,46 & 0,40 \\
\hline 3 & RL649 & 0,13 & 0,01 & 0,05 & 108,78 & 1,36 & 0,43 \\
\hline 4 & RL650 & 0,66 & 0,01 & 0,21 & 239,73 & 2,75 & 1,43 \\
\hline 5 & RL712 & 0,06 & 0,00 & 0,04 & 51,59 & 0,58 & 0,58 \\
\hline
\end{tabular}

Cytokine concentrations in $\mathrm{pg} / \mathrm{ml}$.

Figure 5B.

\begin{tabular}{|l|l|r|r|r|r|r|r|}
\hline No & Patient code & \multicolumn{3}{|c|}{ ACPA- B cells } & \multicolumn{3}{|c|}{ ACPA+ B cells } \\
\cline { 3 - 8 } & & IL-8 & IL-6 & TNFa & IL-8 & IL-6 & TNFa \\
\hline 1 & RL1137 & 85 & 3 & 7 & 225 & 14 & 5 \\
\hline 2 & RL1208 & 174 & 14 & 7 & 1140 & 57 & 220 \\
\hline 3 & RL1219 & 60 & 3 & 18 & 87 & 388 & 128 \\
\hline 4 & RL1224 & 25 & -2 & 7 & 79 & -13 & 46 \\
\hline
\end{tabular}

Values presented as delta MFI

Figure 5C.

ACPA-positive B cell clone

\begin{tabular}{|l|r|r|r|r|r|r|}
\hline Well number & \multicolumn{1}{|c|}{ Fib } & \multicolumn{1}{c|}{ cit-Fib } & \multicolumn{1}{|c|}{ Vin } & \multicolumn{1}{c|}{ cit-Vin } & \multicolumn{1}{c|}{ MBP } & \multicolumn{1}{c|}{ cit-MBP } \\
\hline 1 & 2,34 & 10,25 & 2,44 & 8,26 & 2,93 & 160,16 \\
\hline 2 & 2,83 & 6,87 & 4,31 & 8,16 & 3,23 & 149,82 \\
\hline 3 & 3,52 & 8,85 & 5,98 & 10,25 & 4,01 & 148,88 \\
\hline
\end{tabular}

Concentrations presented in $\mathrm{pg} / \mathrm{ml}$.

Figure 5D.

\begin{tabular}{|l|r|r|}
\hline Well number & \multicolumn{1}{|c|}{ TT+ clone } & \multicolumn{1}{|c|}{ ACPA+ clone } \\
\hline 1 & 28,84 & 847,13 \\
\hline 2 & 27,66 & 779,44 \\
\hline 3 & 29,60 & 865,43 \\
\hline
\end{tabular}


Figure 5E.

\begin{tabular}{|l|r|r|r|r|r|r|r|}
\hline $\begin{array}{c}\text { Well } \\
\text { number }\end{array}$ & $\begin{array}{c}\text { Medium } \\
\text { only }\end{array}$ & $\begin{array}{c}100 \mathrm{ng} / \mathrm{ml} \\
\text { IL-8 }\end{array}$ & $\begin{array}{c}\text { IL-8 }+ \\
\text { Anti- } \\
\text { IL-8 } \\
\mathrm{Ab}\end{array}$ & $\begin{array}{c}\text { ACPA+ } \\
\text { supernatant }\end{array}$ & $\begin{array}{c}\text { ACPA+ } \\
\text { supernatant } \\
+ \text { Anti-IL-8 } \\
\text { Ab }\end{array}$ & $\begin{array}{c}\text { Tetanus } \\
\text { supernatant }\end{array}$ & $\begin{array}{c}\text { supernatant } \\
+ \text { Anti-IL-8 } \\
\text { Ab }\end{array}$ \\
\hline 1 & 61187 & 172278 & 95183 & 102504 & 55395 & 65341 & 59419 \\
\hline 2 & 67711 & 178138 & 84913 & 103369 & 72969 & 80545 & 63041 \\
\hline 3 & & & & 101998 & 68238 & 70022 & 57808 \\
\hline
\end{tabular}

\section{Figure S5B.}

\begin{tabular}{|l|r|r|r|r|r|r|}
\hline \multirow{2}{*}{ No } & \multicolumn{4}{|c|}{ Arthralgia } & \multicolumn{3}{c|}{ Established RA } \\
\cline { 2 - 7 } & $\begin{array}{c}\text { Patient } \\
\text { code }\end{array}$ & $\begin{array}{c}\text { ACPA concentration } \\
\text { (AU/ml) }\end{array}$ & $\begin{array}{c}\text { ACPA+ B cell } \\
\text { frequency (\%) }\end{array}$ & $\begin{array}{c}\text { Patient } \\
\text { code }\end{array}$ & $\begin{array}{c}\text { ACPA concentration } \\
\text { (AU/ml) }\end{array}$ & $\begin{array}{c}\text { ACPA+ B cell } \\
\text { frequency (\%) }\end{array}$ \\
\hline 1 & RL677 & 2563 & 0,0046 & RL549 & 2671 & 0,0029 \\
\hline 2 & RL684 & 1597 & 0,0042 & RL367 & 1279 & 0,0045 \\
\hline 3 & RL685 & 272 & 0,0388 & RL403 & 222 & 0,0087 \\
\hline 4 & RL691 & 1701 & 0,0014 & RL552 & 765 & 0,0013 \\
\hline 5 & RL710 & 569 & 0,0019 & RL351 & 101 & 0,0021 \\
\hline 6 & RL737 & 31 & 0,0016 & RL343 & 765 & 0,0021 \\
\hline
\end{tabular}

\section{Figure S5C.}

\begin{tabular}{|l|r|r|r|}
\hline No & Patient code & ACPA+ B cell frequency (in \%) & ACPA IgG serum concentration (AU/ml) \\
\hline 1 & RL677 & 0,0046 & 2563 \\
\hline 2 & RL684 & 0,0042 & 1597 \\
\hline 3 & RL685 & 0,0388 & 272 \\
\hline 4 & RL691 & 0,0014 & 1701 \\
\hline 5 & RL709 & 0,0008 & 14 \\
\hline 6 & RL710 & 0,0019 & 569 \\
\hline 7 & RL721 & 0,0008 & 19 \\
\hline 8 & RL737 & 0,0016 & 31 \\
\hline
\end{tabular}


Figure S5D.

ACPA+ B cells, arthralgia

\begin{tabular}{|l|l|r|r|r|}
\hline No & Patient code & CD20+ CD27- frequency (in \%) & CD20+ CD27+ frequency (in \%) & CD20- CD27++ frequency (in \%) \\
\hline 1 & RL677 & 17 & 83 & 0 \\
\hline 2 & RL684 & 10 & 86 & 0 \\
\hline 3 & RL685 & 15 & 84 & 1 \\
\hline 4 & RL691 & 20 & 80 & 0 \\
\hline 5 & RL709 & 63 & 38 & 0 \\
\hline 6 & RL710 & 63 & 0 \\
\hline 7 & RL721 & 22 & 78 & 0 \\
\hline 8 & RL737 & 17 & 83 & 0 \\
\hline
\end{tabular}

ACPA+ B cells, recent onset $R A$

\begin{tabular}{|l|l|r|r|r|}
\hline No & Patient code & CD20+ CD27- frequency (in \%) & CD20+ CD27+ frequency (in \%) & CD20- CD27++ frequency (in \%) \\
\hline 1 & ASC003 & 29 & 53 & 0 \\
\hline 2 & ASC005 & 4 & 48 & 44 \\
\hline 3 & ASC006 & 54 & 50 & 1 \\
\hline 4 & ASC008 & 79 & 0 \\
\hline 5 & ASC009 & 17 & 56 & 0 \\
\hline 6 & ASC010 & 41 & 47 & 35 \\
\hline 7 & ASC012 & 8 & 48 & 24 \\
\hline
\end{tabular}

ACPA+ B cells, established RA

\begin{tabular}{|l|l|r|r|r|}
\hline No & Patient code & CD20+ CD27- frequency (in \%) & CD20+ CD27+ frequency (in \%) & CD20- CD27++ frequency (in \%) \\
\hline 1 & RL0343 & 47 & 42 & 11 \\
\hline 2 & RL0346 & 22 & 67 & 11 \\
\hline 3 & RL0347 & 16 & 84 & 0 \\
\hline 4 & RL0349 & 63 & 38 & 0 \\
\hline 5 & RL0351 & 44 & 0 \\
\hline 6 & RL0367 & 56 & 84 & 5 \\
\hline 7 & RL0370 & 41 & 49 & 8 \\
\hline 8 & RL0394 & 53 & 81 & 4 \\
\hline 9 & RL0395 & 38 & 65 & 0 \\
\hline 10 & RL0396 & 19 & 82 & 2 \\
\hline 11 & RL0403 & 32 & 48 & 6 \\
\hline 12 & RL0417 & 60 & 33 \\
\hline 13 & RL0489 & 12 & 64 & 30 \\
\hline 14 & RL0493 & 19 & 50 & 0 \\
\hline 15 & RL0494 & 10 & 67 & 0 \\
\hline 16 & RL0495 & 36 & 47 & 1 \\
\hline 17 & RL0549 & 50 & 75 & 7 \\
\hline 18 & RL0550 & 32 & & 12 \\
\hline
\end{tabular}




\begin{tabular}{|l|l|r|r|r|}
\hline 19 & RL0551 & 15 & 85 & 0 \\
\hline 20 & RL0552 & 33 & 67 & 0 \\
\hline
\end{tabular}

Figure S9.

\begin{tabular}{|l|r|r|r|}
\hline No & Patient code & ACPA- MBC (in MFI) & ACPA+ MBC (in MFI) \\
\hline 1 & RL145 & 7950 & 3107 \\
\hline 2 & RL146 & 7573 & 5741 \\
\hline 3 & RL160 & 930 & 624 \\
\hline 4 & RL167 & 12382 & 3414 \\
\hline 5 & RL569 & 2975 & 2402 \\
\hline 6 & RL570 & 4905 & 1442 \\
\hline 7 & RL573 & 3828 & 3360 \\
\hline 8 & RL624 & 2288 & 725 \\
\hline
\end{tabular}

Figure S10.

TT-specific B cell clone

\begin{tabular}{|l|r|r|r|r|r|r|}
\hline Well number & \multicolumn{1}{|c|}{ Fib } & \multicolumn{1}{c|}{ cit-Fib } & \multicolumn{1}{c|}{ Vin } & \multicolumn{1}{c|}{ cit-Vin } & \multicolumn{1}{c|}{ MBP } & \multicolumn{1}{c|}{ cit-MBP } \\
\hline 1 & 6,67 & 6,77 & 11,24 & 9,75 & 9,35 & 10,15 \\
\hline 2 & 8,46 & 6,67 & 7,57 & 14,95 & 9,85 & 9,95 \\
\hline 3 & 9,05 & 5,88 & 12,44 & 12,34 & 9,45 & 12,14 \\
\hline
\end{tabular}

Concentrations presented in $\mathrm{pg} / \mathrm{ml}$. 
A
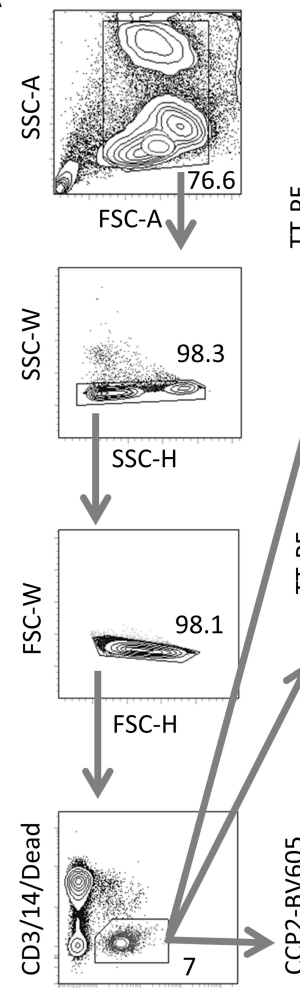

CD19
Pre-incubated

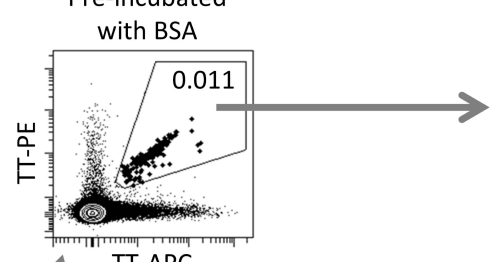

Pre-incubated with TT
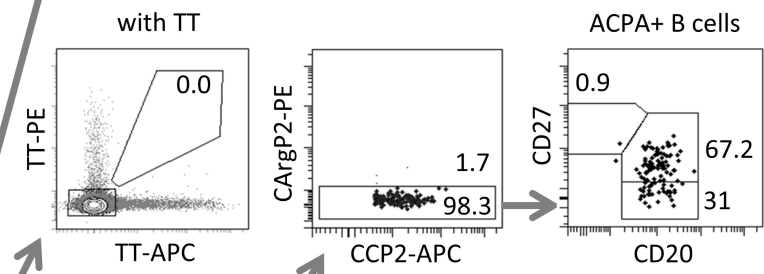

Pre-incubated

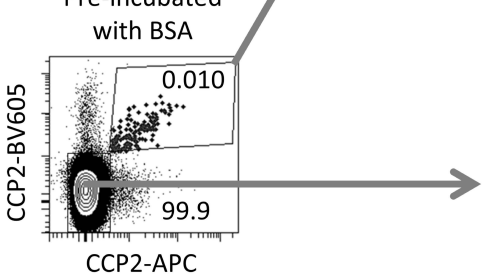

CCP2-APC

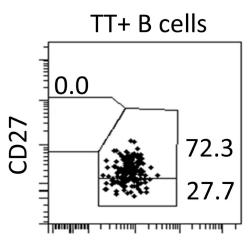

CD20

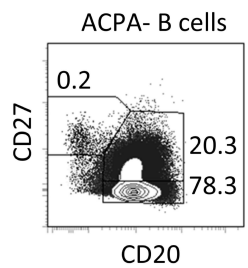
in PBMC and SFMC

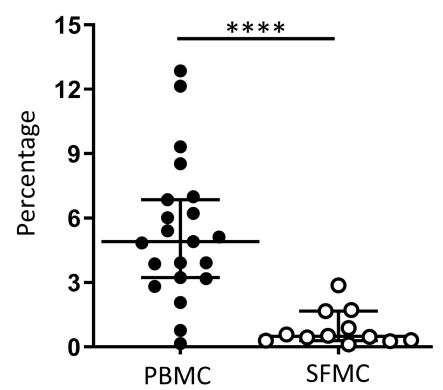

Frequency of antigen-specific $B$ cells in PBMC and SFMC

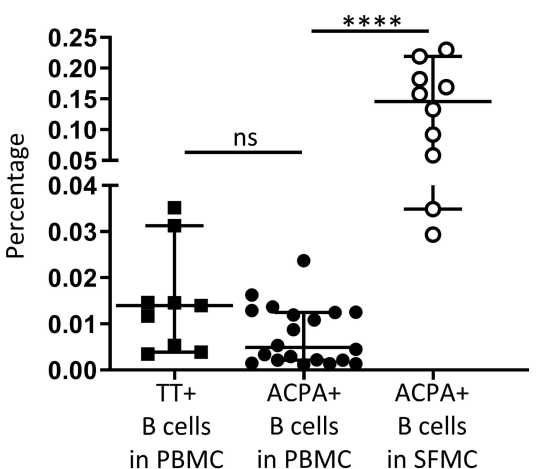

C

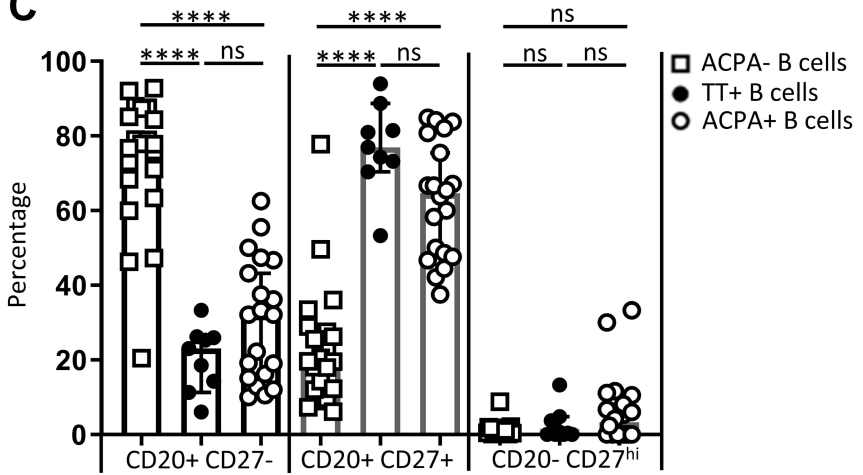

D

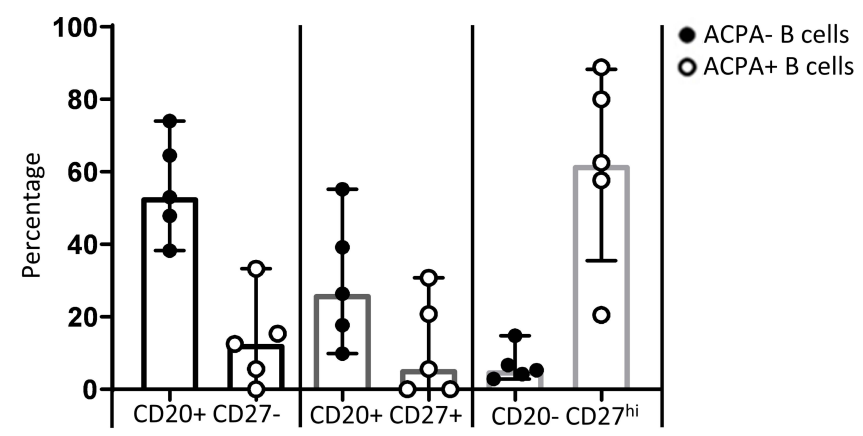

E

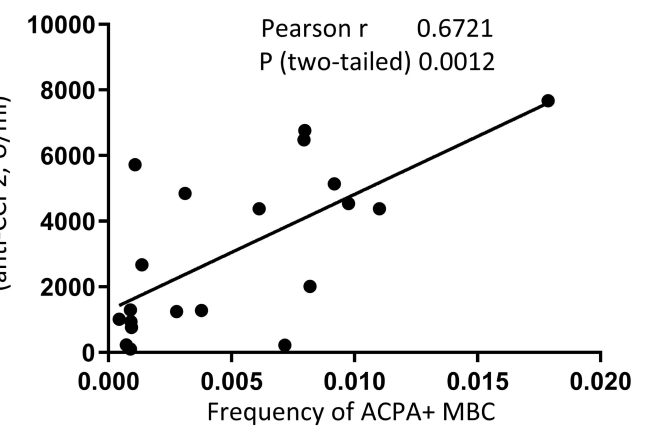

in PBMC 
A
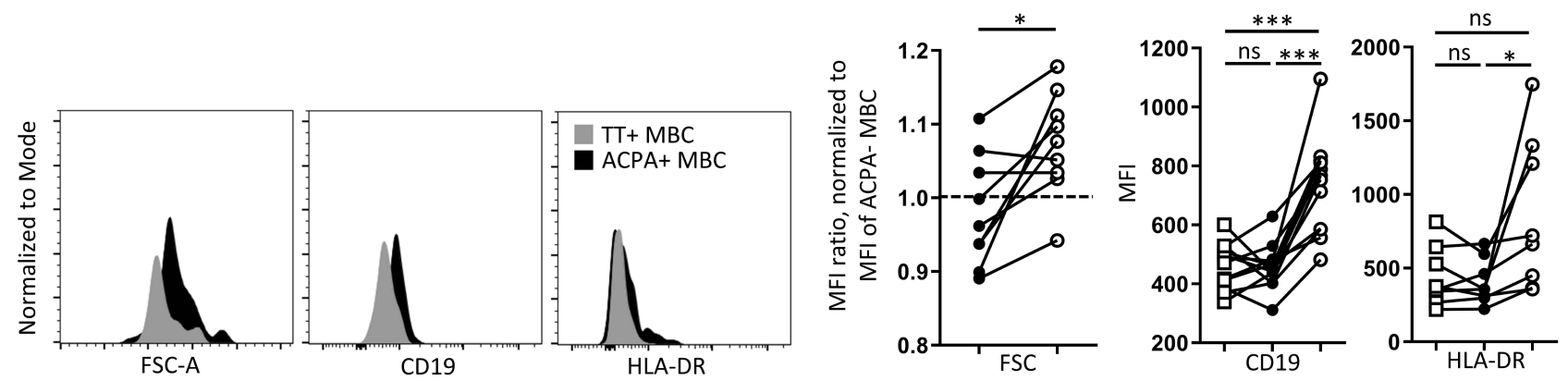

B
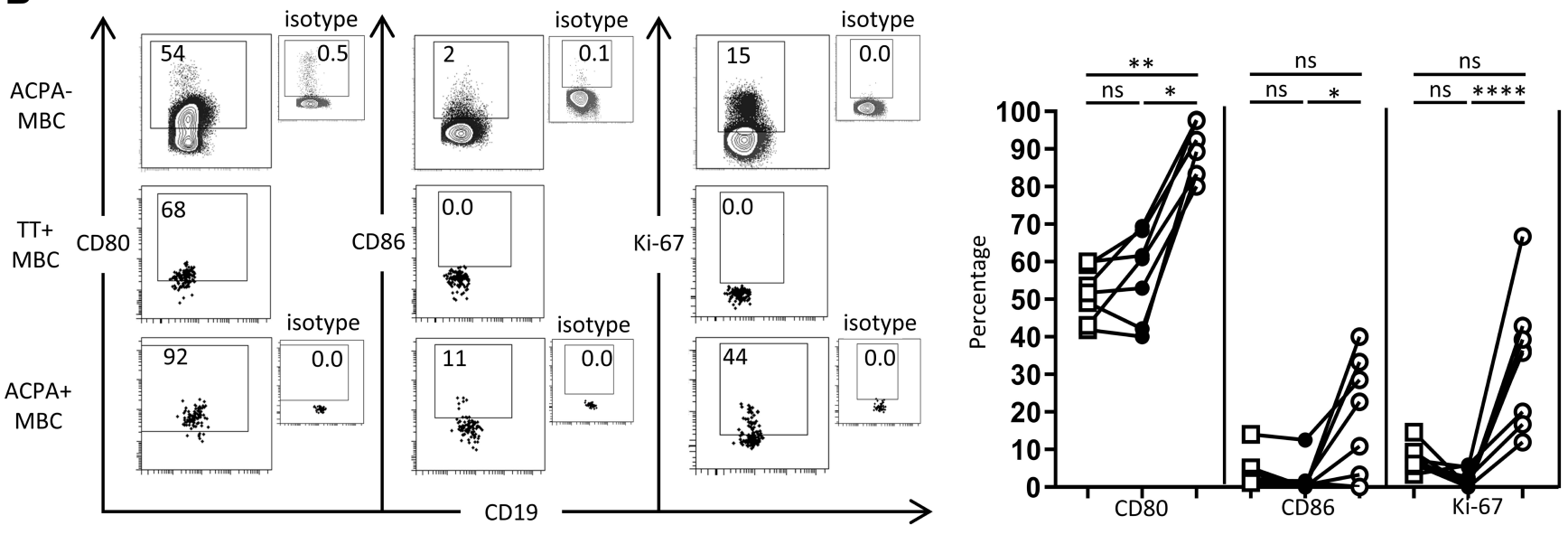

C
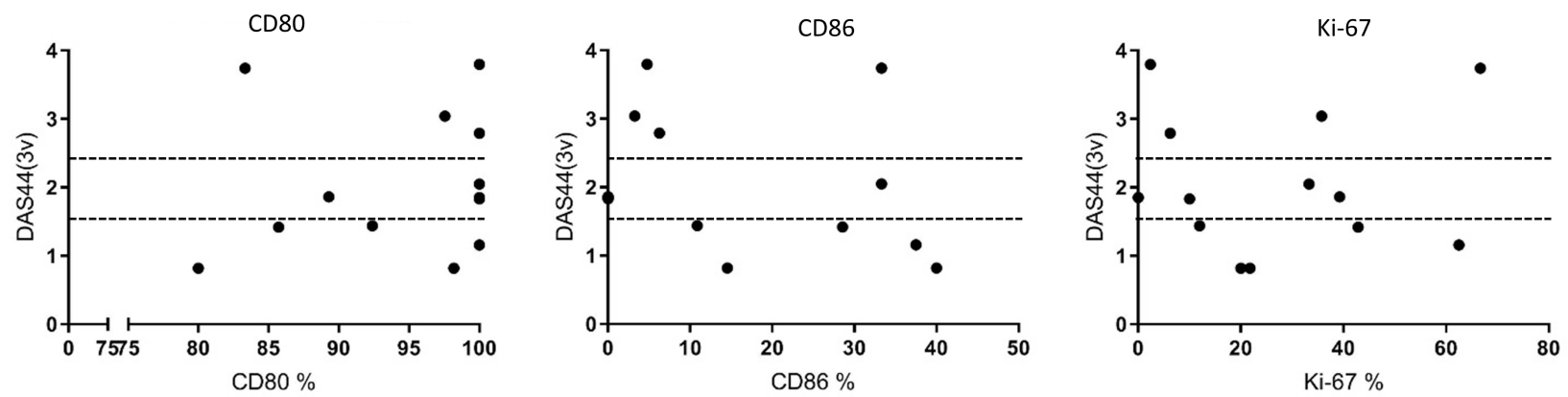

ㅁ ACPA- MBC

- $T T+M B C$

- ACPA+ MBC 
A
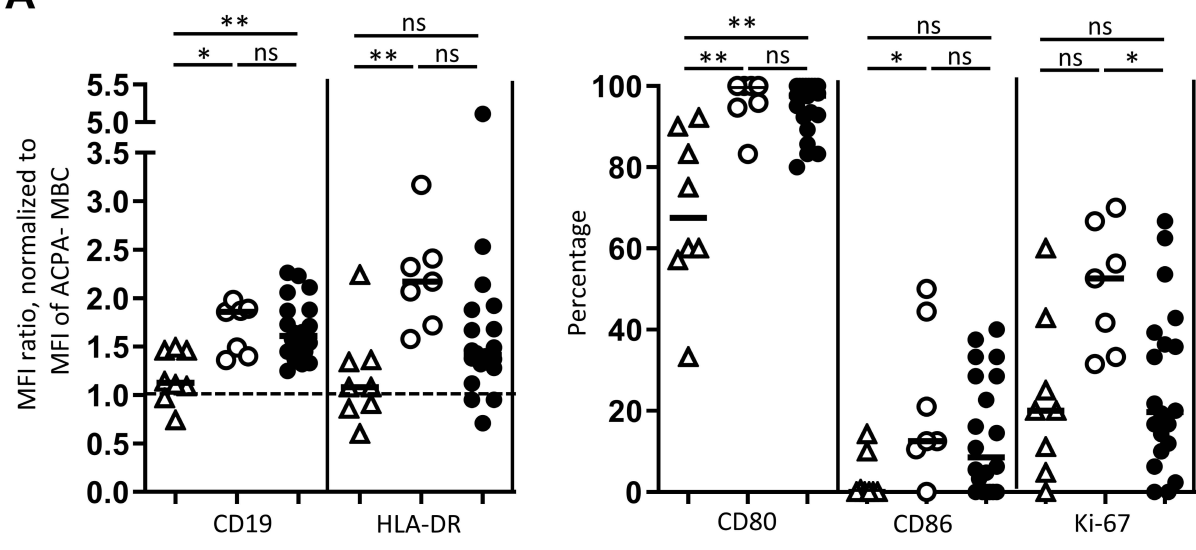

$\triangle A C P A+M B C$, arthralgia

O $A C P A+M B C$, recent onset $R A$

- $A C P A+M B C$, established RA

B
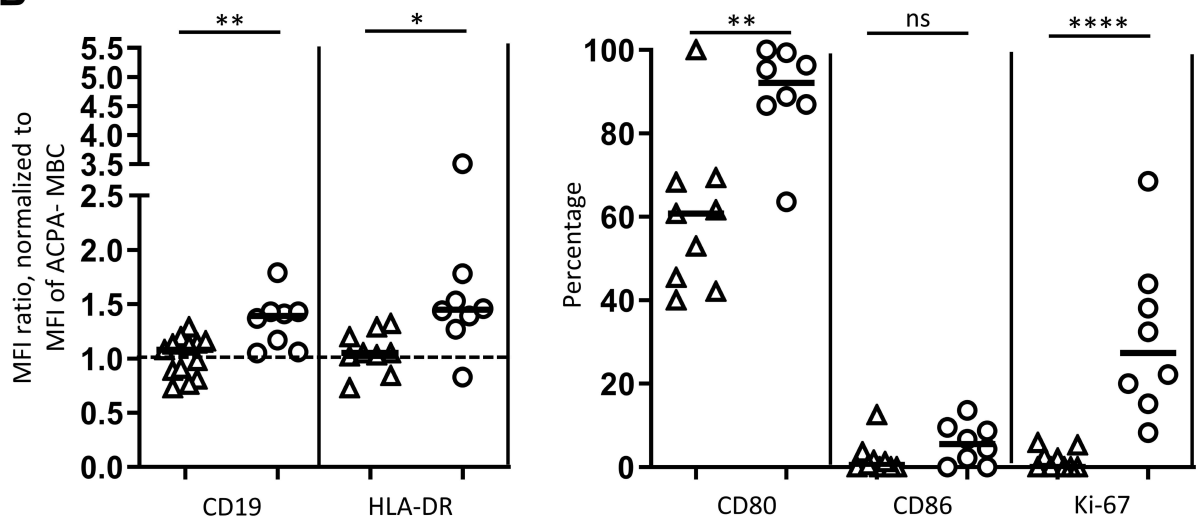

$\Delta T T+M B C$, steady state

O $T \mathrm{TT}+\mathrm{MBC}$, recently vaccinated

C

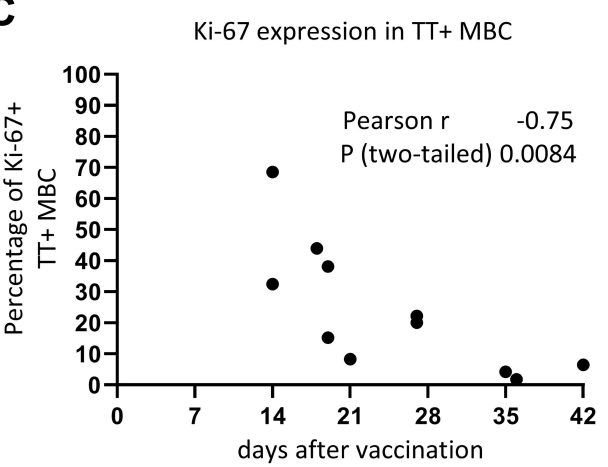




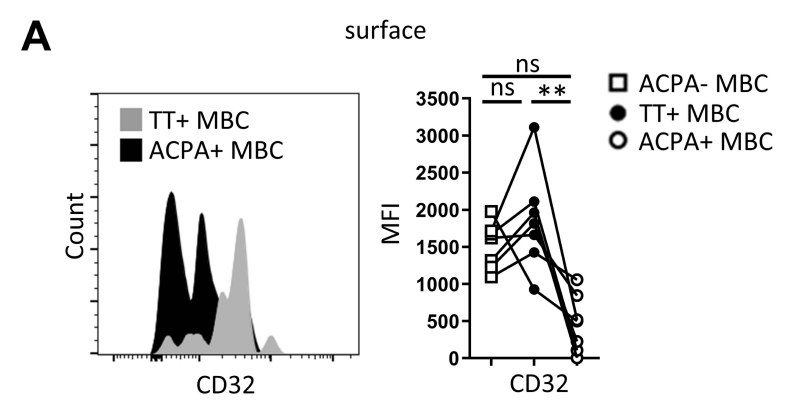

B intracellular
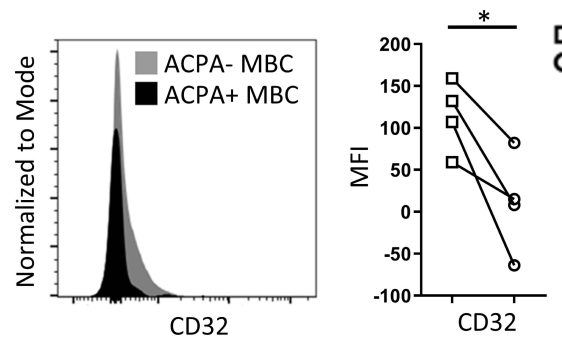
A

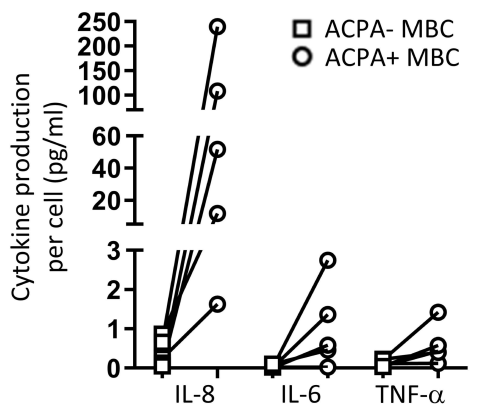

B

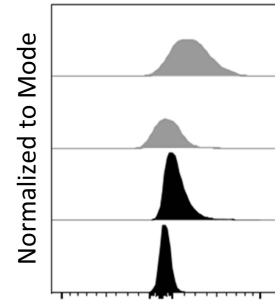

IL-8

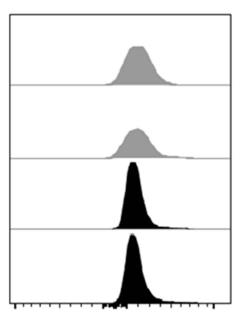

IL-6

C

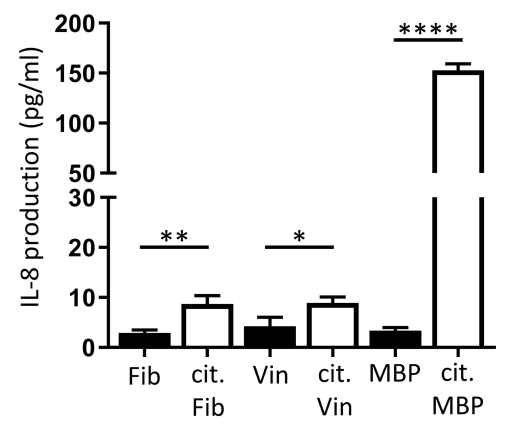

$A C P A+B$ cells in SFMC cytokine staining $A C P A+B$ cells in SFMC isotype staining ACPA-B cells in SFMC cytokine staining ACPA- B cells in SFMC isotype staining TNF- $\alpha$

D

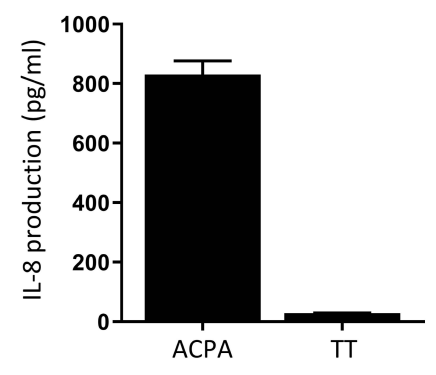

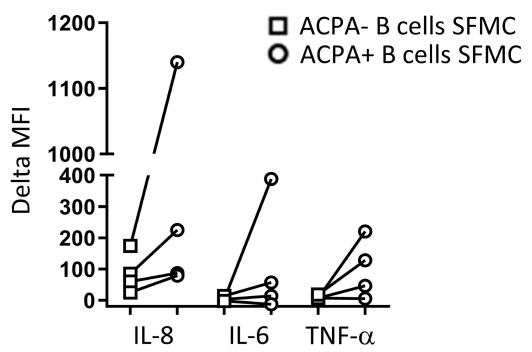

E

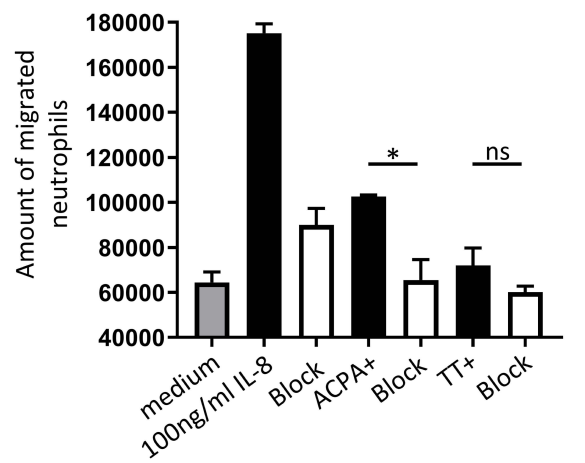

